\title{
O LUGAR DOS GRAFISMOS E DAS REPRESENTAÇÕES NA ARTE PRÉ-COLONIAL AMAZÔNICA ${ }^{1}$
}

\author{
Denise Maria Cavalcante Gomes
}

A partir da primeira década de 2000 interpretações acerca da existência de sociedades complexas na Amazônia pré-colonial, descritas como cacicados (Heckenberger 2005; Neves 2006; Rostain 2010; Roosevelt 1991, 1992, 1999; Schaan 2001a, 2004) começam a conviver com os estudos sobre a arte dessas sociedades. Reflexões geradas a partir das conexões estabelecidas entre a Arqueologia e a Etnologia Indígena, especialmente os estudos com base nos sistemas cosmológicos amazônicos, ampliaram as possibilidades de se correlacionar a arte de culturas arqueológicas tardias no que tange à materialização de noções tais como a transformação das formas e dos corpos às ontologias ameríndias (Descola 2005; Viveiros de Castro 1996, 2002), abrindo portas para uma abordagem mais ampla sobre as morfologias sociais do passado (Gomes 2007, 2012, 2016; Barreto 2008).

Contribuições no campo da antropologia da arte têm oferecido aportes acerca da agência dos objetos, compreendida como a mediação desses artefatos rituais no processo social, levando em conta sua capacidade de encantamento (Gell 1992, 1998). Por outro lado, diversos trabalhos etnológicos têm analisado a arte como linguagem estética, bem como a relação entre artefatos e pessoas no mundo ameríndio, considerando seus sistemas cosmológicos e, por fim, as capacidades diferenciadas de agência desses mesmos objetos, vistos ainda como seres animados ou subjetividades (Barcelos Neto 2004, 2008; Belaunde 2013; Fausto 2013; Fausto \& Severi 2016; Gordon 2011; Hugh-Jones 2009, 2016; Lagrou 1996, 1998, 2007, 2009, 2011a, 2011b, 2012, 2013, 2016; Miller 2009; Müller 1992; Santos-Granero 2009a, 2009b; Van Velthem 1995, 2001, 2003, 2009, 2013; Vidal 1992).

A maior parte dos trabalhos arqueológicos acerca da arte das sociedades amazônicas pré-coloniais tardias atribui à linguagem artística um sentido funcional, em consonância com uma tradição de estudos iconográficos partilhada com a história da arte, compreendendo as imagens como representações associadas a estratégias políticas, considerando-as uma expressão 
direta de sociedades hierarquizadas e centralizadas. Desse modo, os objetos rituais foram frequentemente vistos como instrumentos de comunicação utilizados pelas elites a fim de reforçar seu poder político durante cerimônias ou reafirmar genealogias em contextos funerários (Barreto 2008; Guapindaia 2001; Roosevelt 1991, 1992, 1999; Schaan 1997, 2001a, 2004, 2008).

O propósito deste artigo ${ }^{2}$ é examinar aspectos formais ligados à materialidade dos regimes de figuração de artefatos cerâmicos de duas sociedades pré-coloniais tardias (800-1600 A.D.): Santarém e as Estearias do Maranhão. Embora a comparação se baseie em exemplos de sociedades que acumulam um conhecimento arqueológico bastante desigual, a intenção é mostrar que, apesar das especificidades, ambas apresentam determinadas semelhanças formais. O estudo em questão baseia-se numa análise da composição dos elementos formais e decorativos, além de uma aproximação com as ontologias amazônicas. Ela se beneficia dos debates sobre a arte indígena contemporânea, bem como dos estudos recentes no campo da arqueologia amazônica que incorporam conexões entre arte e cosmologias. Ao lado das características estilísticas, os resultados revelam noções comuns dessas sociedades pré-coloniais acerca das concepções morfológicas dos artefatos, que podem ser explicadas a partir da relação existente entre a noção de fabricação de artefatos e a fabricação de pessoas na Amazônia. Por fim, hipóteses são propostas sobre o significado das configurações estéticas observadas na longa duração, tendo em vista que estas possivelmente refletem diferentes ideologias e formas de organização social.

\section{A arte indígena contemporânea}

Taylor e Viveiros de Castro (2006) assinalam a existência de uma arte indígena contemporânea não figurativa na Amazônia, com predominância da abstração, que evita a representação na expressão bidimensional. Essa mesma tendência tem sido reconhecida por Lagrou (1996, 1998, 2002, 2011a, 2011b) que, a partir de seus estudos sobre a arte dos Kaxinawa, aponta que essa ênfase na abstração estaria relacionada com a utilização de motivos que ajudam a compor superfícies que contêm os corpos ou mesmo os objetos, sendo que estes não representam corpos. Esta tendência do grafismo que adere a suportes contrasta com a figuração minimalista dos artefatos tridimensionais que constituem efígies de humanos ou animais e que consistem em modelos reduzidos de corpos. Tais artefatos-corpo são vistos pela autora como índices, dentro da complexa relação existente no mundo ameríndio entre figura, imagem e corpo, que não simbolizam, mas, ao contrário, significam e agem. 
Taylor e Viveiros de Castro (2006) fundamentam esta ideia ao se referirem ao princípio da incompletude que rege as concepções sobre o corpo de acordo com as ontologias amazônicas, sendo que para os grupos que habitam as terras baixas a forma é determinada pelo olhar que se tem sobre o corpo e pela relação que os outros estabelecem com ele. Sobre a linguagem visual utilizada entre os grupos contemporâneos para falar dos corpos, os autores assim a descrevem:

Essas culturas rejeitam propiciar uma forma material, separada do corpo, às relações que se estabelecem ao redor dele; contrariamente àquelas da Nova Guiné, da África Ocidental ou da Europa, as sociedades da bacia amazônica produzem poucas imagens tangíveis do corpo sob a forma de gravuras, de esculturas ou de pinturas. Elas não fabricam representações do corpo, elas de fato fabricam os corpos. Os utensílios são pensados, descritos e quase sempre decorados como corpos. A "obra de arte" que importa na Amazônia é o corpo humano (Taylor \& Viveiros de Castro 2006:150).

Outro traço dessa arte que enfatiza a abstração é a capacidade perceptiva engendrada pelos grafismos e pelas imagens, implicando operações formais que permitem ao perceptor mudar de ponto de vista (Lagrou 1998, 2007, 2011a). Tais operações estão ligadas à noção de transformabilidade das formas, sendo tal característica central para a compreensão do estilo, que estabelece uma inegável conexão com as ontologias ameríndias animistas (Descola 2005) e perspectivistas (Viveiros de Castro 1996, 2002).

O exemplo da arte kaxinawa explorado por Lagrou consiste num estilo gráfico no qual não há figura e contrafigura que se possa fixar, mas uma dinâmica sinestésica do desenho. Este estilo, segundo a autora, é marcado pelo efeito studium-punctum (Lagrou 2007, 2013), ou pela repetição simétrica de elementos abstratos que ocupam toda a superfície do suporte e, em determinado momento, insere um ponto ou detalhe assimétrico que marca a singularidade dessa estética, visando ao agenciamento do olhar. O estilo geral é comum a outros grupos da Amazônia Ocidental - os chamados povos do desenho (os Shipibo, os Conibo, os Maburo e os Piro), instaurando uma constante tensão entre aquilo que é mostrado e o que não é, o que tem relação com a transformação dos corpos e com o caráter composto dos seres.

De acordo com Lagrou, sua hipótese é a de que existe uma continuidade entre os ameríndios, especialmente na Amazônia, dos modos de figuração, de um lado, e dos grafismos, de outro, no quadro de uma ontologia transformacional, cuja ligação entre grafismo e figuração consiste numa relação de transformabilidade. O grafismo sendo um caminho ótico para a visualização de imagens virtuais. Ou ainda, o grafismo que captura o olhar do observador 
a fim de inserir imagens mentais exteriores a ele, sendo esse um movimento acessível somente às pessoas que partilham do mesmo quadro de referências (Lagrou 2007, 2009, 2011a, 2011b, 2013).

Embora essa relação de continuidade entre abstração e figuração (imaginada), acima descrita, se mostre adequada para descrever a arte dos Kaxinawa e de outros grupos amazônicos portadores de sistemas de desenhos complexos (Gow 1989; Lagrou 2011a:70, 2013:70), entre as sociedades pré-coloniais, especialmente no médio e baixo Amazonas, encontram-se diversas expressões gráficas, tanto mais antigas, a exemplo da cerâmica Pocó (Gomes 2011; Guapindaia 2008; Neves 2008), quanto mais tardias, como Santarém (Gomes 2001, 2002), Konduri (Guapindaia 2008) e Marajó (Schaan 2004; Barreto 2008), que inegavelmente apresentam representações figurativas mais explícitas. A abstração pode ainda surgir num estilo híbrido, associada ao figurativismo, como na cerâmica Marajoara. O estilo Marajoara apresenta figurações que foram reduzidas a abstrações, algumas delas constituindo elementos mínimos de significação (Schaan 1997). Além disso, as abstrações podem ocupar um lugar secundário nos estilos eminentemente figurativos, ou ainda ocorrer em classes específicas de objetos, como em Santarém. Uma análise mais detida demonstra, de fato, a presença de ambas as expressões estéticas no período pré-colonial.

\section{A arte xamânica de Santarém}

A cultura Santarém começou a ser estudada sistematicamente somente a partir de 1980, por meio das escavações realizadas por Anna Roosevelt e associados na área urbana da cidade de Santarém, no Pará. Ela propôs que nessa região teria se desenvolvido uma sociedade complexa, hierarquizada e com centralização política, cujas aldeias menores, localizadas em uma ampla região, entre o rio Tapajós e Amazonas, se organizavam em torno de uma capital situada no centro de Santarém (Quinn 2004; Roosevelt 1992, 1999).

Pesquisas posteriores conduzidas pela autora, entre 2000 e 2014, delimitaram grandes sítios (Aldeia e Porto) hoje localizados em área urbana, e complementaram a cronologia regional que se inicia por volta de 2000 a.C., cuja fase mais tardia se situa entre 1000 e 1600 A.D. Ao lado das aldeias extensas e da grande densidade de sítios, os dados enfatizam a importância dos artefatos cerimoniais e do xamanismo como instituição cosmopolítica, evidenciando uma arte mobiliária distribuída em um vasto território com cerca de $20.000 \mathrm{~km}^{2}$ ao longo dos rios Amazonas e Tapajós (Gomes 2016). Estruturas arquitetônicas estão ausentes, especialmente envolvendo grandes 
deslocamentos de terra, cuja construção teria exigido esforços coletivos, a exemplo dos tesos de Marajó (Schaan 2004, 2008) ou dos campos elevados das Guianas (Rostain 2010).

Os artefatos cerimoniais da cultura Santarém, PA foram analisados a partir de um corpus bastante amplo proveniente de coleções museológicas (MAE-USP: 1.200 artefatos, sendo 84 inteiros; Museu Nacional-UFRJ: 800 artefatos, sendo 35 inteiros) e de cerca de 13.700 fragmentos originários de 30 sítios arqueológicos dessa mesma região (Gomes 2016). O potencial informativo dos artefatos inteiros, armazenados nas coleções museológicas, deve ser destacado no que tange a estudos envolvendo aspectos formais e iconográficos. Já os acervos originários das escavações sistemáticas, compostos basicamente de fragmentos, possuem um valor muito mais contextual, pois é através deles que conseguimos inferir em que tipo de atividade os artefatos estavam envolvidos. Escavações recentes no sítio Aldeia (Gomes 2016) e nos sítios Porto (Gomes \& Luiz 2013; Quinn 2004; Schaan \& Alves 2015), bem como em outros sítios da região (Schaan 2016), têm demonstrado grande variabilidade de contextos de deposição desses artefatos, com destaque para estruturas intencionalmente cavadas que podem armazenar tanto artefatos utilitários quanto cerimoniais em área doméstica, nesse caso, bastante fragmentados. Os bolsões rituais costumam conter unicamente artefatos cerimoniais, em muitos casos intencionalmente quebrados, como no exemplo da estrutura 1 identificada no sítio Aldeia (Tabela 1).

A tabela 1 apresenta a quantificação de artefatos pré-coloniais relativos à ocupação da fase Santarém, recuperados no sítio Aldeia pela autora, sendo este o mais importante sítio dessa cultura conforme apontado por Nimuendaju (1949, 2004), embora atualmente coberto pela ocupação urbana na cidade de Santarém. Foram excluídos os artefatos das camadas históricas (louças, cerâmicas, artefatos de ferro etc.) e das camadas anteriores à ocupação Santarém (Pocó). As escavações indicam uma proporção reduzida de fragmentos relacionados aos três tipos de vasos cerimoniais identificados por Barata (vasos de cariátides, globular e gargalo) nas unidades de escavação, em comparação com outros fragmentos de artefatos utilitários, decorados e sem decoração. Apenas na estrutura 1 se observa a concentração dos vasos acima citados, sendo os fragmentos associados a três artefatos, que estavam acompanhados de uma lâmina de machado polida. 
Tabela 1: Densidade cerâmica: Tipos e formas do Sítio Aldeia - Santarém, PA

\begin{tabular}{|c|c|c|c|c|}
\hline Unidade & Fase & Tipos / Formas & Número de Fragmentos & Porcentagem (\%) \\
\hline $\begin{array}{l}\text { Estrutura } 1 \\
(0,70 \times 0,70 \mathrm{~m})\end{array}$ & Santarém & $\begin{array}{l}\text { Total } \\
\text { Vaso globular } \\
\text { Vaso de cariátides } \\
\text { Vaso de gargalo }\end{array}$ & $\begin{array}{l}149 \\
88 \\
38 \\
23\end{array}$ & $\begin{array}{l}100,00 \\
60,00 \\
25,00 \\
15,00\end{array}$ \\
\hline $1(2 \times 2 \mathrm{~m})$ & Santarém & $\begin{array}{l}\text { Total } \\
\text { Sem decoração } \\
\text { Pintura vermelha } \\
\text { Inc. e ponteado Estatueta } \\
\text { Estatueta } \\
\text { Assador }\end{array}$ & $\begin{array}{c}747 \\
551 \\
177 \\
12 \\
5 \\
2\end{array}$ & $\begin{array}{c}100,00 \\
73,80 \\
23,70 \\
1,60 \\
0,60 \\
0,30\end{array}$ \\
\hline $2(2 \times 2 \mathrm{~m})$ & Santarém & $\begin{array}{l}\text { Total } \\
\text { Sem decoração } \\
\text { Pintura vermelha } \\
\text { Inc. e ponteado } \\
\text { Vaso de cariátides } \\
\text { Estatueta } \\
\text { Vaso globular } \\
\text { Pintura policr. } \\
\text { Assador } \\
\text { Impressão de Esteira }\end{array}$ & $\begin{array}{l}397 \\
252 \\
84 \\
22 \\
10 \\
8 \\
8 \\
8 \\
5 \\
1\end{array}$ & $\begin{array}{l}100,00 \\
63,45 \\
21,00 \\
5,55 \\
2,50 \\
2,00 \\
2,00 \\
2,00 \\
1,25 \\
0,25\end{array}$ \\
\hline $3(2 \times 2 \mathrm{~m})$ & Santarém & $\begin{array}{l}\text { Total } \\
\text { Pintura vermelha }\end{array}$ & $\begin{array}{l}7 \\
7\end{array}$ & $\begin{array}{l}100,00 \\
100,00\end{array}$ \\
\hline $4(2 \times 2 \mathrm{~m})$ & Santarém & $\begin{array}{l}\text { Total } \\
\text { Sem decoração } \\
\text { Pintura vermelha } \\
\text { Estatueta } \\
\text { Inc. e Ponteado } \\
\text { Vaso de cariátides } \\
\text { Vaso globular } \\
\text { Assador }\end{array}$ & $\begin{array}{c}723 \\
501 \\
144 \\
25 \\
24 \\
22 \\
4 \\
3\end{array}$ & $\begin{array}{l}100,00 \\
69,30 \\
19,92 \\
3,45 \\
3,30 \\
3,05 \\
0,55 \\
0,43\end{array}$ \\
\hline $5(2 \times 2 \mathrm{~m})$ & Santarém & $\begin{array}{l}\text { Total } \\
\text { Sem decoração }\end{array}$ & $\begin{array}{l}18 \\
18\end{array}$ & $\begin{array}{l}100,00 \\
100,00\end{array}$ \\
\hline $6(2 \times 1 \mathrm{~m})$ & Santarém & $\begin{array}{l}\text { Total } \\
\text { Sem decoração } \\
\text { Pintura vermelha } \\
\text { Inc. e ponteado } \\
\text { Vaso de cariátides }\end{array}$ & $\begin{array}{c}907 \\
624 \\
277 \\
4 \\
2 \\
\end{array}$ & $\begin{array}{c}100,00 \\
68,80 \\
30,60 \\
0,4 \\
0,2 \\
\end{array}$ \\
\hline $7(2 \times 2 \mathrm{~m})$ & Santarém & $\begin{array}{l}\text { Total } \\
\text { Sem decoração } \\
\text { Pintura vermelha } \\
\text { Inc. e ponteado } \\
\text { Vaso de cariátides }\end{array}$ & $\begin{array}{c}429 \\
338 \\
76 \\
13 \\
2\end{array}$ & $\begin{array}{l}100,00 \\
78,80 \\
17,72 \\
3,02 \\
0,46\end{array}$ \\
\hline $8(2 \times 2 \mathrm{~m})$ & Santarém & $\begin{array}{l}\text { Total } \\
\text { Sem decoração } \\
\text { Pintura vermelha } \\
\text { Inc. e ponteado } \\
\text { Vaso de cariátides }\end{array}$ & $\begin{array}{l}78 \\
67 \\
5 \\
4 \\
2 \\
\end{array}$ & $\begin{array}{c}100,00 \\
85,90 \\
6,42 \\
5,12 \\
2,56\end{array}$ \\
\hline $9(2 \times 2 \mathrm{~m})$ & Santarém & $\begin{array}{l}\text { Total } \\
\text { Sem decoração } \\
\text { Pintura vermelha }\end{array}$ & $\begin{array}{c}41 \\
37 \\
4\end{array}$ & $\begin{array}{c}100,00 \\
90,25 \\
9,75\end{array}$ \\
\hline $10(2 \times 2 \mathrm{~m})$ & Santarém & $\begin{array}{l}\text { Total } \\
\text { Sem decoração } \\
\text { Pintura vermelha }\end{array}$ & $\begin{array}{l}31 \\
23 \\
8\end{array}$ & $\begin{array}{l}100,00 \\
74,20 \\
25,80\end{array}$ \\
\hline $11(2 \times 2 \mathrm{~m})$ & Santarém & Total & 0 & 0 \\
\hline $12(2 \times 2 \mathrm{~m})$ & Santarém & $\begin{array}{l}\text { Total } \\
\text { Sem decoração }\end{array}$ & $\begin{array}{l}2 \\
2 \\
\end{array}$ & $\begin{array}{l}100,00 \\
100,00\end{array}$ \\
\hline $13(1 \mathrm{x} 1 \mathrm{~m})$ & Santarém & $\begin{array}{l}\text { Total } \\
\text { Sem decoração }\end{array}$ & $\begin{array}{l}3 \\
3\end{array}$ & $\begin{array}{l}100,00 \\
100,00\end{array}$ \\
\hline $14(1 \times 1 \mathrm{~m})$ & Santarém & $\begin{array}{l}\text { Total } \\
\text { Sem decoração } \\
\text { Pintura vermelha } \\
\text { Estatueta } \\
\text { Inc. e Ponteado } \\
\text { Assador } \\
\text { Rodela de fuso }\end{array}$ & $\begin{array}{l}33 \\
18 \\
9 \\
2 \\
2 \\
1 \\
1\end{array}$ & $\begin{array}{c}100,00 \\
54,50 \\
27,50 \\
6,00 \\
6,00 \\
3,00 \\
3,00\end{array}$ \\
\hline $15(2 \times 1 \mathrm{~m})$ & Santarém & $\begin{array}{l}\text { Total } \\
\text { Sem decoração } \\
\text { Pintura vermelha }\end{array}$ & $\begin{array}{c}37 \\
31 \\
6\end{array}$ & $\begin{array}{l}100,00 \\
84,00 \\
16,00\end{array}$ \\
\hline
\end{tabular}


A cerâmica cerimonial de Santarém tem um estilo icônico, representacional, caracterizado pela existência de vasos com apêndices tridimensionais antropomorfos e zoomorfos (animais de presa ou grandes predadores), que materializam corpos, alguns deles em estado de transformação. Esses artefatos recaem na classificação de efígie ou artefato-corpo, proposto por Lagrou (2011b) para se referir a modelos reduzidos de corpos, mantendo ainda a sugestão de Roosevelt (1988) em contexto pré-colonial. No caso dos animais ou animais antropomorfizados, eles seguem o esquema cabeça e cauda, em que a vasilha faz às vezes de corpo (Figura 1). Mais raras são as estatuetas realistas de homens sentados em bancos, portando adornos corporais e chocalhos (Figura 2). Outra classe distinta são as pequenas estatuetas femininas estilizadas. Alguns vasos organizados de modo mais elaborado são a corporificação de conceitos sobre o mundo - vaso de cariátides, dividido em três patamares cósmicos (Figura 3) e vasos de gargalo (Figura 4), sendo que estes últimos têm um caráter narrativo (Gomes 2007:203).

Figura 1: Vaso globular. Efígie de onça, cultura Santarém. Acervo MAE-USP. Adaptado de Gomes (2002).Desenho: Luciana Witovisk Gussella

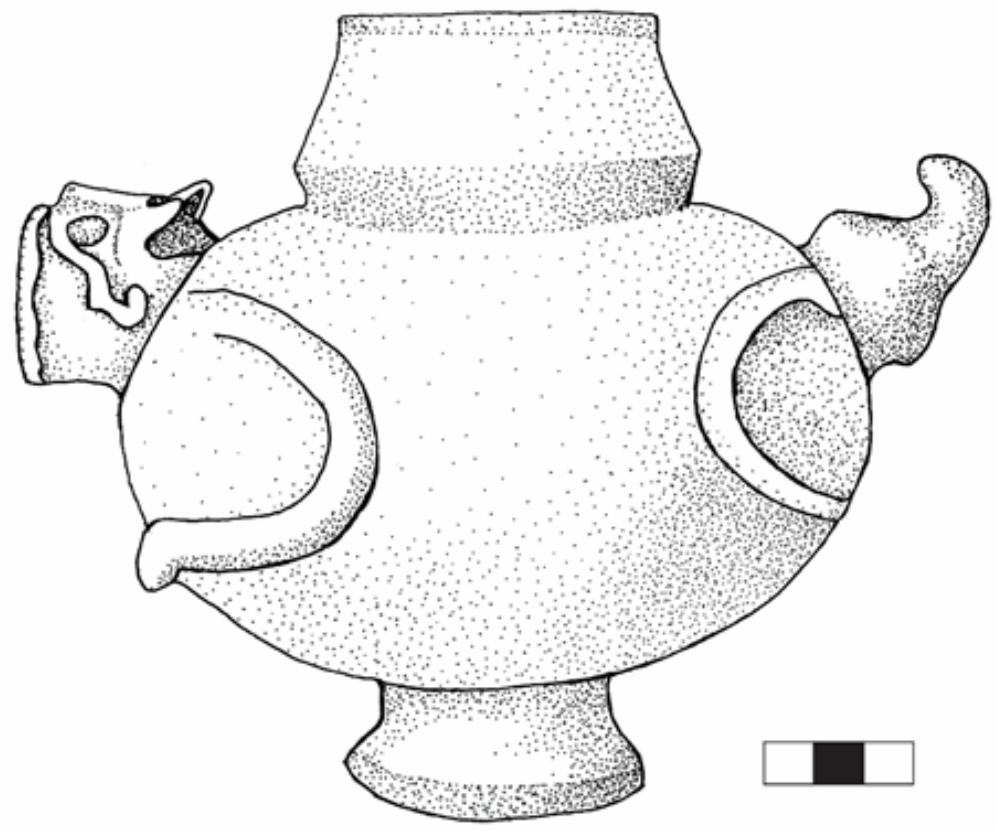


Esses artefatos cerâmicos foram identificados como objetos que constituem uma parafernália ligada ao xamanismo. Eles apresentam uma iconografia com elementos diagnósticos que enfatizam a transformação corpórea, os deslocamentos para outros patamares cósmicos guiados por animais auxiliares, e os rituais envolvendo performances ligadas à rememoração de mitos e conceitos cosmológicos, sugerindo essa associação. Outras evidências arqueológicas são instrumentos musicais em cerâmica. Por fim, referências etno-históricas complementam as informações existentes com outra classe de objetos: pedras, corpos mumificados e estruturas de armazenamento ritual.

Figura 2: Estatueta naturalista de homem sentado, com adornos corporais. Cultura Santarém. Acervo Museu Nacional - UFRJ. Desenho: Luciana Witovisk Gussella

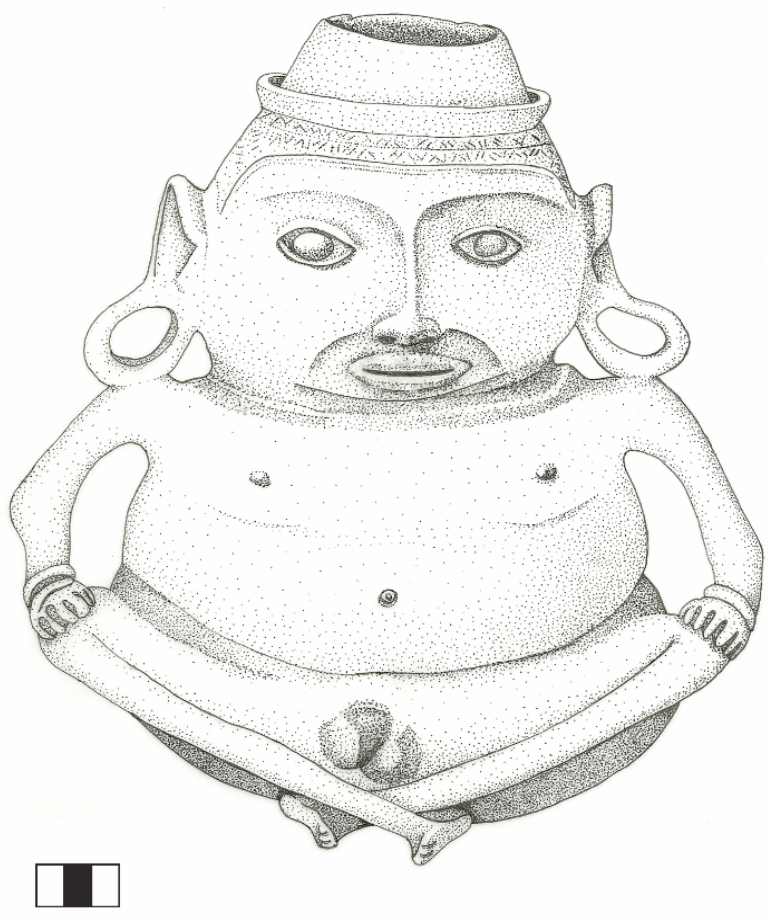


Figura 3: Vaso de cariátides. Cultura Santarém. Artefato que remete à organização do cosmos em camadas. A borda e a base do vaso apresentam padrões abstratos incisos. Acervo MAE-USP, adaptado de Gomes (2002). Desenho de Luciana Witovisk Gussella

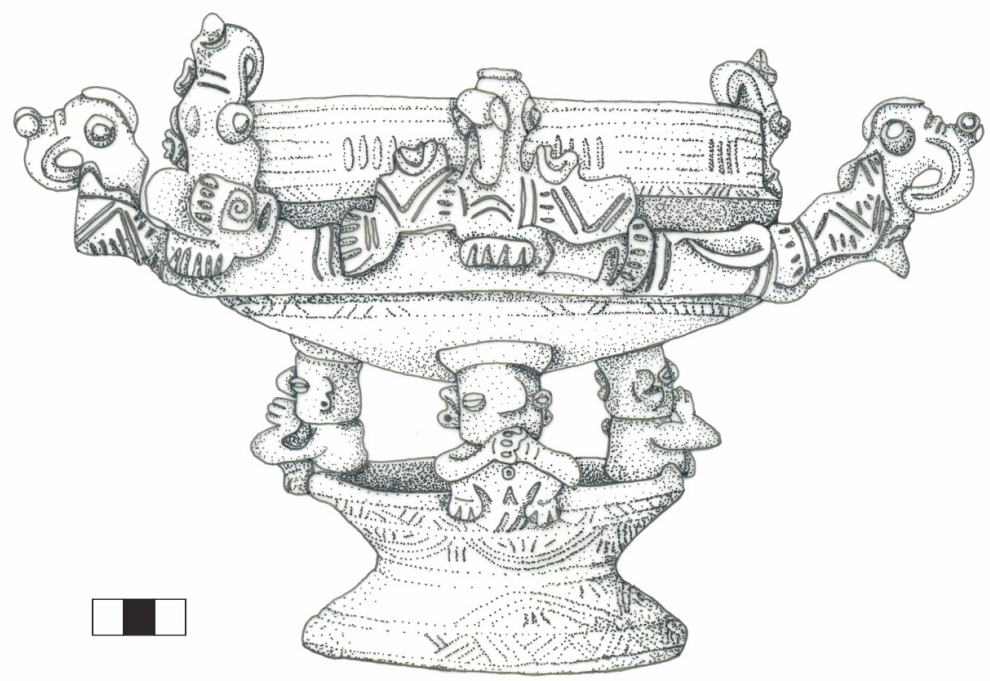

Figura 4: Vaso de gargalo, de caráter narrativo. Cultura Santarém. Além dos elementos tridimensionais figurativos, o vaso exibe padrões abstratos incisos no gargalo e na base. Acervo MAE-USP, adaptado de Gomes (2002). Desenho de Luciana Witovisk Gusella

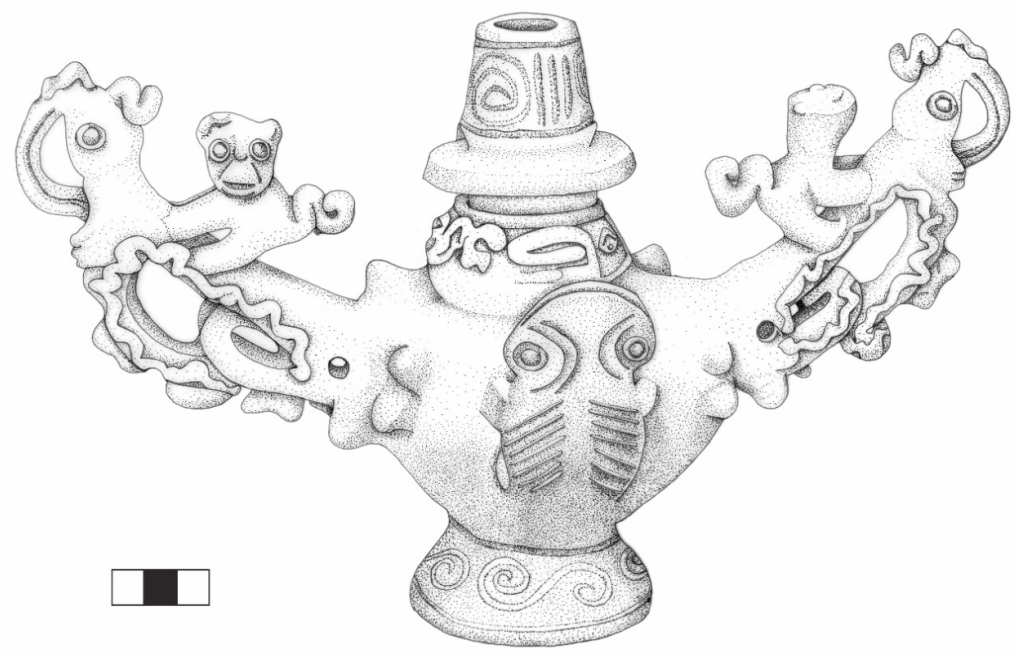


A compreensão desses artefatos se deu por meio de uma abordagem iconográfica que buscou estabelecer uma analogia com as ontologias amazônicas contemporâneas, de caráter predatório, tendo como premissa a existência de um fundo cosmológico comum de grande duração cronológica e ampla distribuição geográfica, o que possibilitou postular a existência de uma unidade estética ameríndia. Entretanto, essa unidade estética se expressa de modo desigual, com diferenças no que tange às morfologias sociais e às especificidades, além da completa ausência dessas noções em algumas sociedades (Gomes 2012:134). A ênfase na ideia de metamorfose corpórea, presente nas figurações desses objetos (Figura 5), permitiu a sua associação com o conceito antropológico de perspectivismo ameríndio (Viveiros de Castro 1996, 2002).

Figura 5: Estatueta de um ser em metamorfose corpórea: cabeça e braços humanos com adornos e corpo de serpente. Cultura Santarém. Acervo MAE-USP, adaptado de Gomes (2012).

Desenho de Luciana Witovisk Gussella
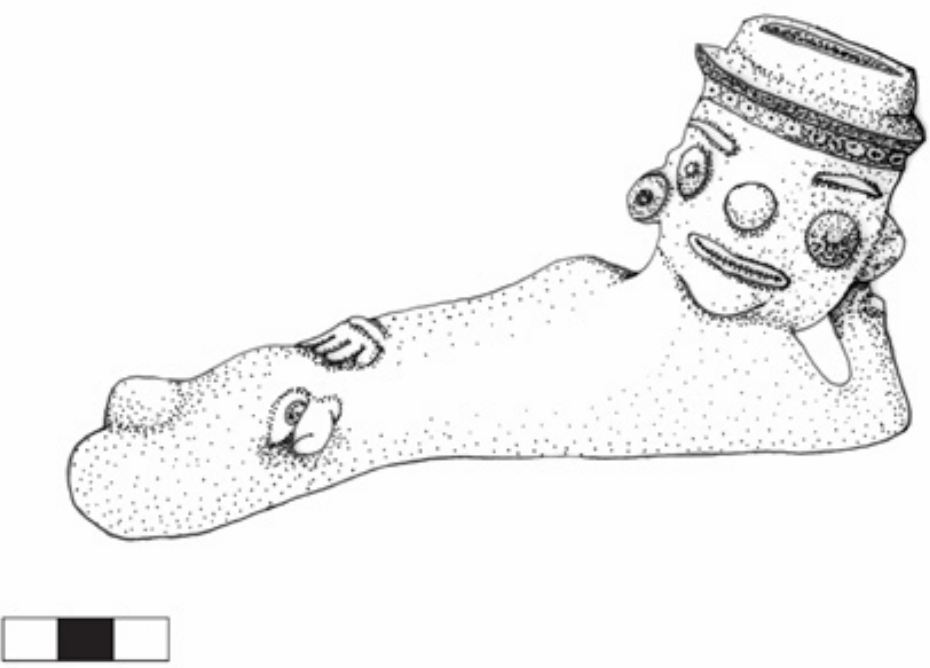
Análises anteriores sobre as características formais desse estilo cerâmico e o reconhecimento das representações figurativas, especialmente das espécies zoológicas, facilitaram esse percurso (Gomes 2001, 2002). As primeiras abordagens sobre a arte cerâmica de Santarém foram de natureza descritiva e tipológica (Palmatary 1960; Barata 1950, 1951, 1953a, 1953b), seguidas por trabalhos que especularam sobre os possíveis significados mitológicos das figurações zoomorfas (McDonald 1972) e, finalmente, análises tecnológicas (Guapindaia 1993).

Os principais objetos cerimoniais foram reunidos por Barata numa tipologia que se mantém até o presente: 1. vasos de cariátides: vasilha que contém uma cuia rodeada por apêndices tridimensionais de urubus-reis zoomorfos e híbridos, sustentada por três figuras humanas do sexo feminino que se apoiam sobre uma base; 2 . vasos de gargalo: objeto de pequena capacidade contendo um gargalo e geralmente dois apêndices laterais em forma de cabeças de jacarés, que se assemelham a asas, sobre as quais figuram diversos animais; 3. vasos globulares: vasilhas esféricas que consistem em efígies de animais ou de seres em transformação; e 4. estatuetas antropomorfas. Esses mesmos objetos foram descritos por Barata segundo suas partes constituintes e a identificação das diversas figurações tridimensionais.

Barata (1953a) também reproduziu os grafismos incisos encontrados nas bordas e nas bases desses mesmos artefatos, atribuindo aos desenhos abstratos significados (rã, cobra, coruja e tartaruga etc.) - procedimento referido por Boas (1996 [1927]) como reading in, e criticado por considerar a projeção de significados simbólicos nos desenhos abstratos, desprovidos de referencial etnográfico, completamente arbitrária. Entretanto, uma das contribuições mais importantes de Barata (1950:26-27) foi o reconhecimento de noções estéticas presentes nesses objetos, que mais tarde puderam ser interpretadas como sugestivas de instabilidade corporal ou de processos de transformação corpórea. Destacam-se os apêndices contendo faces antropomorfas e que, conforme o ângulo de visualização, mudam sua expressão; os urubus-reis meio homem meio pássaro; os seres híbridos, homens com feições ou atributos zoomorfos, como caudas; criaturas míticas, a exemplo do urubu-rei de duas cabeças, figura cujo corpo partilha uma cabeça humana e outra de urubu-rei.

Boomert (2001:130), ao discutir os significados das representações figurativas de aves de rapina na iconografia dos artefatos cerâmicos pré-coloniais no Caribe e na Amazônia, aponta a presença de apêndices de harpia e de urubus-reis como indicadores da importância do xamanismo ameríndio. Eles foram vistos como seres auxiliares dos xamãs em suas 
viagens pelo mundo espiritual. Especialmente a versão bicéfala do urubu-rei tem, de acordo com a mitologia ameríndia (homem que se casa com um urubu-rei e vai visitar seus parentes no patamar celeste), um caráter ambíguo em torno da humanidade, ligado, de um lado, à iniciação xamânica e, de outro, à tensão existente quanto à posição social do genro e às obrigações que este deve ter para com o sogro. Dentre as versões do mito, existem aquelas que apresentam o urubu-rei sogro como um canibal devorador de duas cabeças, sendo este tema, de acordo com o autor, conhecido nas Guianas, no Baixo Amazonas, no Alto Xingu e no Brasil Central.

Na iconografia de Santarém, a harpia aparece em objetos para servir, do tipo cuia com pedestal, contendo pintura policrômica e sendo bastante elaborados. Já o urubu-rei bicéfalo surge em uma variação dos vasos de cariátides, em sua condição ambivalente (ave de asas abertas com uma cabeça de animal e outra humana). Por outro lado, a versão simples do urubu-rei figura não só no vaso de cariátides, mas também em numerosos apêndices de vasos de gargalo, sendo menos frequentes as representações de cabeças de urubu-rei contendo pequenas aves sobrepostas, que poderiam ser vistas como duplos de animais, presentes em figuras estilizadas na iconografia konduri do Baixo Amazonas, igualmente comum no Baixo Orinoco (séries Barrancas), nas Guianas e no Caribe.

Quanto aos padrões abstratos incisos, eles ocorrem em pequenas bandas colocadas nas bordas e nas bases dos vasos de cariátides, de gargalo, globulares e em algumas tigelas e pratos. Em sua maior parte, são padrões que apresentam diferentes tipos de simetria, sendo os mais comuns os movimentos de translação, a simetria bilateral e o reflexo espelhado (Rice 1987:261), formados por motivos como semicírculos, volutas duplas ou abertas com terminação retilínea, alternados com linhas verticais ou transversais cruzadas (Figura 6). 
Figura 6: Padrões abstratos incisos da cultura Santarém. A, B, D - motivos em simetria de translação; $\mathrm{C}$ - motivos organizados em simetria bilateral. Acervo MAE-USP, adaptado de Gomes (2002). Digitalização dos grafismos: Angislaine Freitas Costa

A

\section{Alm}

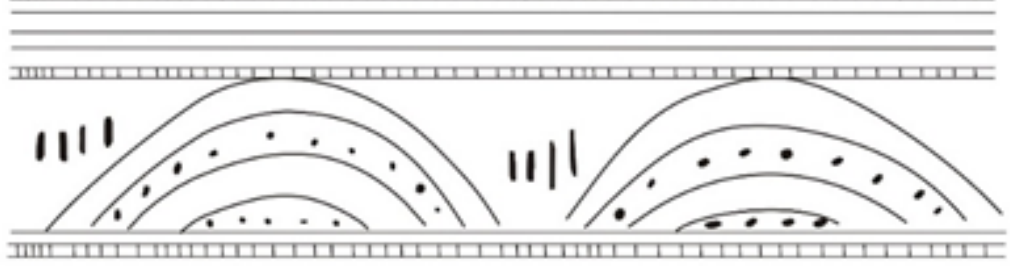

B
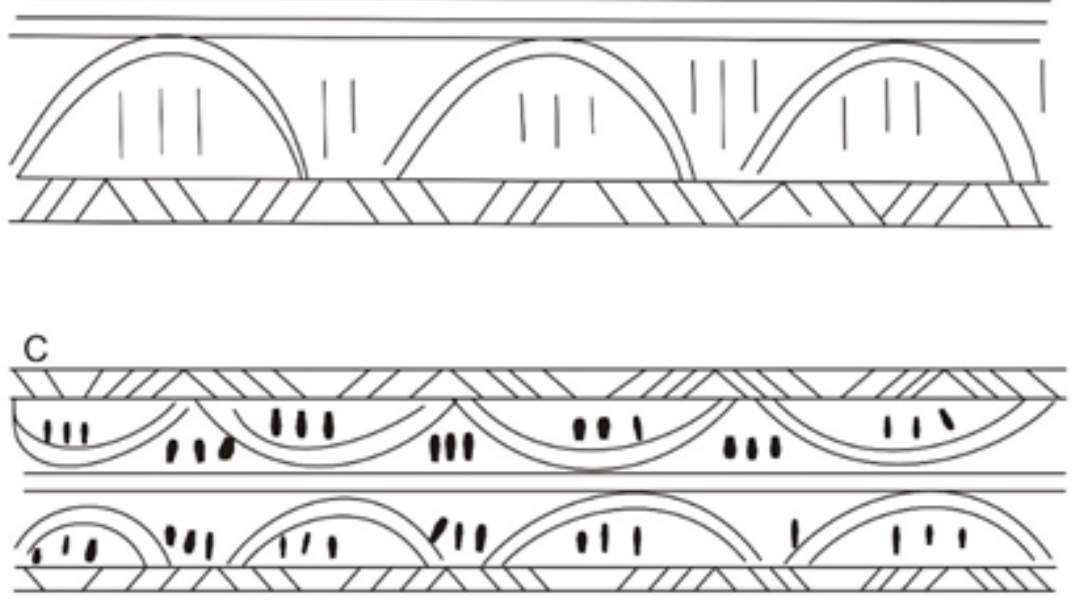

D

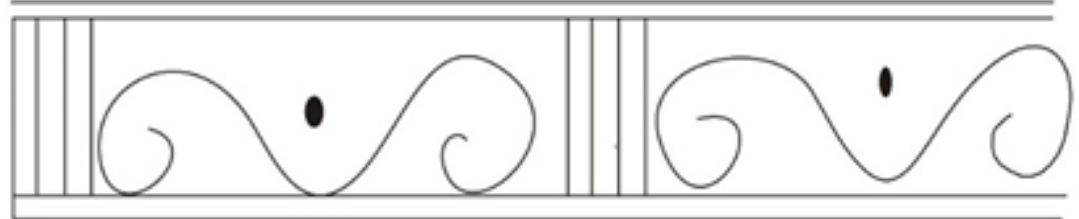


No que tange aos grafismos abstratos existentes nos artefatos com pintura policrômica - vermelha e preta sobre branco - eles surgem em grandes vasilhas de serviço coletivo, em vasos efígie de onça e em taças, em padrões simétricos, compostos por combinações volutas abertas, ondulações simples, linhas de ponteados (Figura 7), além da combinação de linhas paralelas verticais e esferas, presentes no vaso efígie de onça, o que constitui uma mimetização da pelagem do animal. Estes padrões abstratos dos artefatos pintados são contemporâneos dos artefatos incisos, que se sobressaem pela representação figurativa, cujo contexto de escavação da referida estrutura ritual do sítio Aldeia, em Santarém, esclareceu esta questão (Gomes 2010:225, 2016).

Figura 7: Roll-out de padrões abstratos pintados em vasilhas da cultura Santarém. A e C volutas com terminação aberta, sendo A simetricamente organizada em reflexo lateral, alternada com motivos em simetria bilateral; B, D e E apresentam linhas verticais fechando os campos que contêm elementos lineares ou pontos; G consiste numa figuração. A, B e G - Acervo MAE-USP, adaptado de Gomes (2002); C, D, E, F, Acervo Museu Nacional-UFRJ. Digitalização dos grafismos: Angislaine Freitas Costa
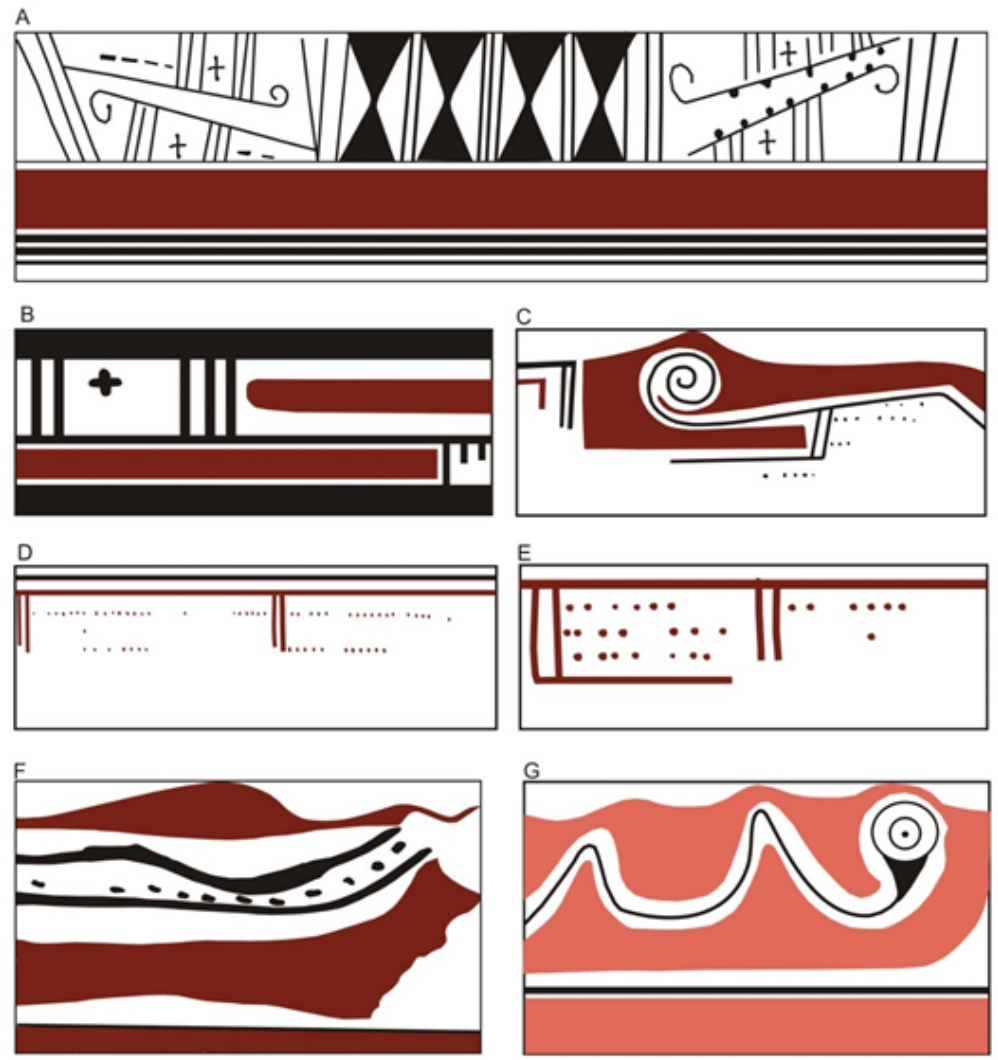
Outra classe, além dos padrões abstratos e das figurações tridimensionais, está presente em vasilhas e pratos para serviço coletivo, vasilhas para conter bebidas e potes miniaturas, que exibem grafismos aplicados associando elementos abstratos a outros figurativos. Eles apresentam uma repetição simétrica de motivos, como ondulações, rãs, serpentes e faces antropomorfas, evidenciando uma categoria intermediária entre a abstração bidimensional e a figuração tridimensional (Figura 8).

Figura 8: Grafismos aplicados da cultura Santarém. A, C, D - motivos figurativos em simetria de translação; B - banda contendo motivos figurativos aplicados (serpentes), limitando outro tipo de motivos abstratos incisos, organizados a partir de simetria bilateral, alternados com um segundo tipo de motivos em simetria de translação. Acervo MAE-USP. Adaptado de Gomes (2002). Digitalização dos grafismos: Angislaine Freitas Costa
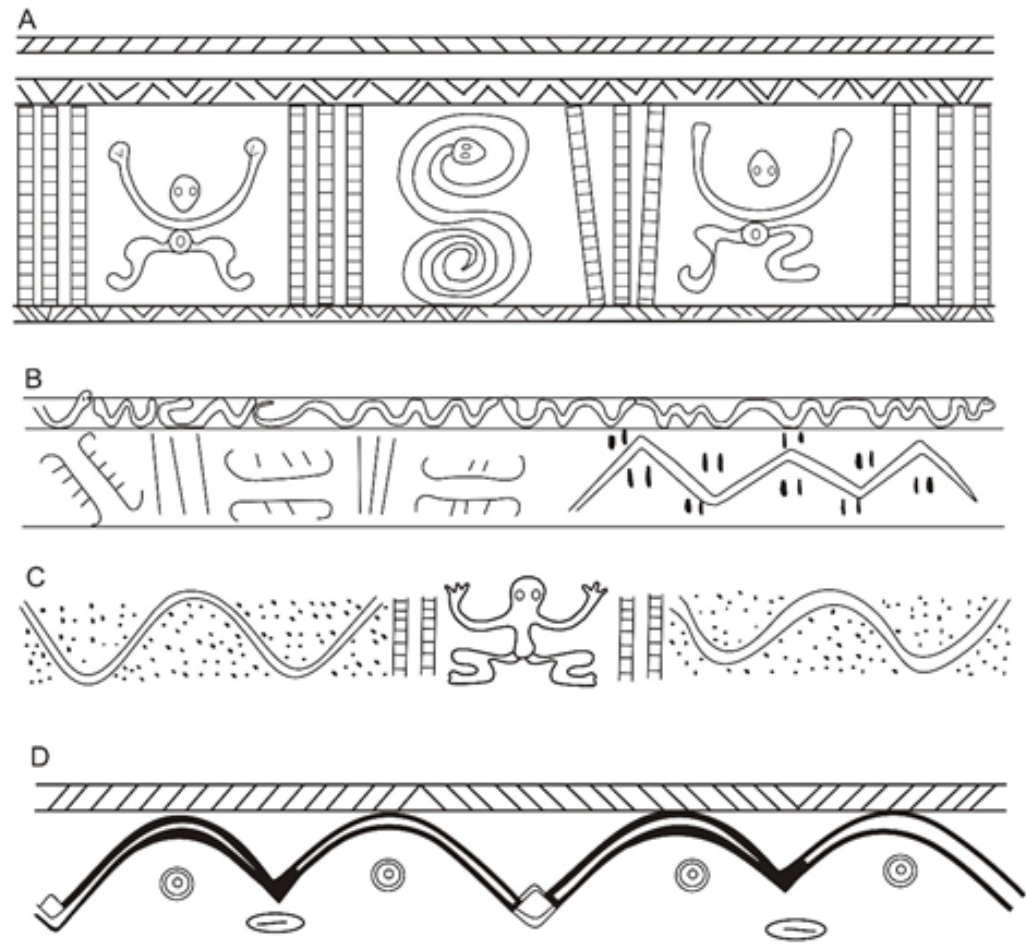
O que fica evidente ao considerarmos os regimes de figuração dos artefatos rituais da cultura Santarém é, em primeiro lugar, a ênfase nas diversas figurações, especialmente as estatuetas antropomorfas, as efígies zoomorfas ou artefatos-corpo, os vasos de conteúdo conceitual e narrativo, além das imagens de transformação corpórea.

Outro aspecto relevante é a coexistência da abstração com a figuração, bem como a materialização das mesmas ideias em diferentes técnicas. Por outro lado, em objetos cerâmicos mais raros, aparentemente destinados ao serviço coletivo, a abstração presente nos artefatos pintados, embora sugira uma expressão independente, apresenta conexão com os artefatos tridimensionais, especialmente com os vasos de conteúdo conceitual e narrativo, uma vez que existem padrões abstratos semelhantes em ambas as classes de artefatos.

Embora a discussão central deste artigo seja a caracterização dos regimes de figuração de dois diferentes estilos cerâmicos, questões relativas à correspondência das expressões estéticas dos objetos, às cosmologias e às formas de organização social são igualmente relevantes. No que se refere a Santarém, o conjunto dos objetos rituais cerâmicos aqui descritos coloca inicialmente em relevo uma ontologia predatória que enfatiza a transformabilidade das formas, a troca de perspectivas entre humanos, animais e espíritos, e que se aproxima do xamanismo do tipo horizontal conforme definido por Hugh-Jones (1994).

No entanto, outra gama de artefatos é mencionada pelos missionários dos séculos XVII e XVIII que conviveram com os Tapajó em Santarém: são as pedras que eram cultuadas - provavelmente objetos semelhantes às pedras xamânicas que incorporam espíritos jaguares familiarizados, descritas por Santos Granero (2009b:108) - mas especialmente os corpos conservados de ancestrais mumificados, que eram mantidos em determinadas estruturas por especialistas e reverenciados em rituais envolvendo oferendas e danças. Existem também menções à ingestão ritual dos ossos triturados desses antepassados misturados à bebida (Betenderof 1910:353-354; João Daniel 1976:238).

Ainda que tais evidências não tenham sido documentadas pela arqueologia, as referências etno-históricas às pedras, aos corpos mumificados e aos xamãs que a eles se dedicavam sugerem um paralelo com as tendências complementares do xamanismo na sociedade Tukano (horizontal e vertical) descritas por Hugh Jones (1994, 2009:54), que ao lado dos yai ou xamãs-jaguar compreendem a existência do kumu, figura mais próxima da função sacerdotal que se dedica às relações associadas à ancestralidade, de caráter mais hierárquico. Estes são elementos que reforçam a caracterização de 
Santarém como uma sociedade complexa, portadora de objetos de grande elaboração simbólica, cuja comparação com os Tukano ilumina o entendimento das relações possíveis de serem estabelecidas com as diferentes classes de objetos descritos, assim como permite postular a existência de cosmologias híbridas no passado pré-colonial.

\section{Casas, corpos e objetos sobre as águas}

A cerâmica das estearias do Maranhão, juntamente com suas especificidades, apresenta alguns pontos de convergência comparados à cultura Santarém. Os artefatos que fazem parte da análise aqui apresentada integram uma importante coleção, denominada "Excursão Raymundo Lopes", armazenada no Museu Nacional-UFRJ, cujo pesquisador realizou levantamentos e coletas em diversos sítios da Baixada Maranhense, reconhecendo prontamente a filiação amazônica da cerâmica (Lopes 1924, 1931, 1970). O corpus analisado é bem preservado, sendo composto por 123 artefatos inteiros e parcialmente inteiros e está relacionado a um conjunto de numerosos sítios pré-coloniais, cujas moradias se estabeleceram em áreas lacustres longe das margens, mais especificamente dentro dos lagos, sobre palafitas ou esteios de madeiras, sendo por este motivo denominados de estearias. Assim sendo, o interesse no estudo desta coleção reside em sua condição de preservação e qualidade dos artefatos, e pelo fato de pesquisas arqueológicas sistemáticas terem sido retomadas recentemente gerando grande interesse em avançar no conhecimento sobre o modo de vida dessa sociedade que construía suas aldeias sobre as águas. A arte inegavelmente é um dos aspectos relevantes.

Nos anos 1970 o Museu Paraense Emílio Goeldi deu início a pesquisas no sítio Lago Cajari, cujos resultados recuperaram informações sobre a morfologia dos sítios e das casas, definindo as principais características da cerâmica por meio do estabelecimento da fase Cajari, tendo ainda obtido uma datação de 570 d.C. a partir de esteios de madeira (Corrêa et al. 1991; Simões 1981; Simões \& Araújo Costa 1978). Leite Filho (2010) realizou uma caracterização das diferentes ocupações da região ao longo do tempo, incluindo as estearias. Entretanto, pouco se sabe sobre essas ocupações lacustres no que se refere à organização social e aos aspectos associados à subsistência, cuja investigação arqueológica tem avançado recentemente a partir das pesquisas realizadas por Navarro $(2013,2015)$ visando à identificação e ao mapeamento espacial dos sítios, bem como à construção de uma cronologia e ao estudo da cerâmica, com datações recentemente obtidas entre 775 e 1045 d.C. (Navarro 2015). 
Devido ao contexto de moradias suspensas sobre palafitas e da deposição arqueológica no meio dos lagos, estruturas domésticas e rituais são inexistentes, salvo urnas funerárias encontradas em locais distantes, a cerca de $1 \mathrm{~km}$ das margens dos lagos. A julgar por suas qualidades estéticas, os objetos analisados devem ter sido empregados durante cerimônias. Eles apresentam grafismos abstratos e representações iconográficas figurativas que permitem igualmente abordar aspectos relativos às cosmologias amazônicas, podendo ser divididos em três principais classes. Em primeiro lugar, surgem as vasilhas abertas, de pequenas capacidades. São elas efígies de animais - morcegos, jacaré, cachorro do mato, urubu-rei, pássaros, sapos, peixe, porco do mato, mamíferos não reconhecíveis e arraias - constituídas a partir do mesmo esquema cabeça, corpo e cauda do animal, cujos apêndices são colocados sobre a borda em extremidades opostas do artefato (Figura 9). Ao lado do morcego, o animal mais frequentemente identificado, destacam-se predadores, como o jacaré. Mais raras são as vasilhas em formato de vegetais (folhas).

Figura 9: Efígies de animais (artefatos-corpo) de vasilhas das Estearias do Maranhão. A, B, C: morcegos; D, E, F: urubu-rei; G: aves; H: jacaré. Acervo Museu Nacional-UFRJ. Digitalização: Angislaine Freitas Costa. Fotos: Sarah Hissa
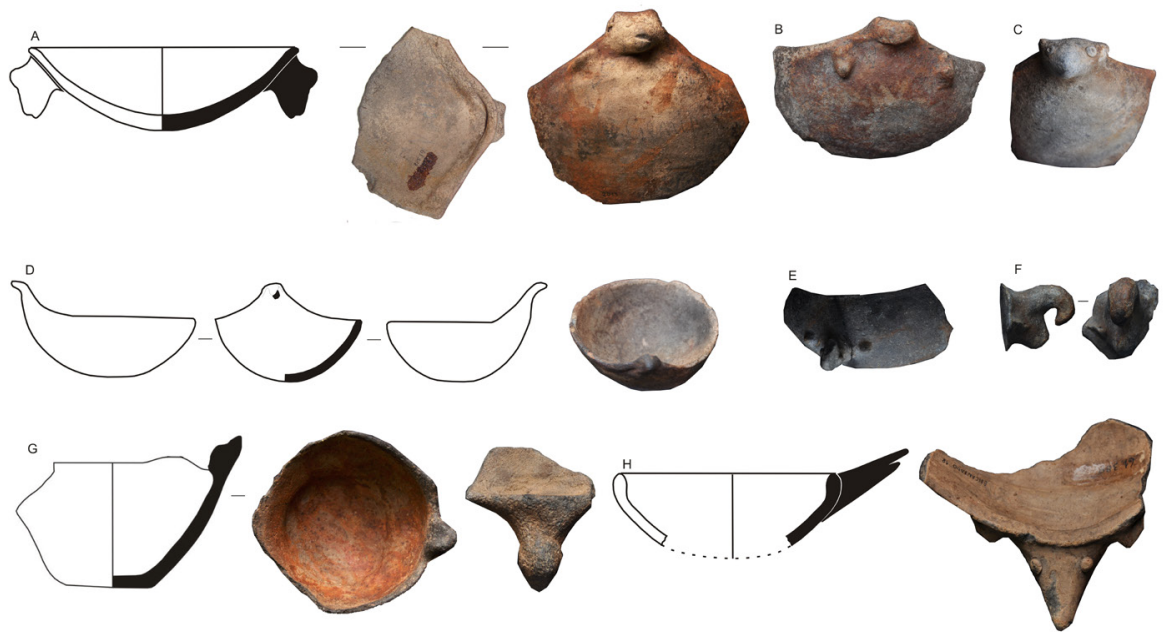
Em segundo lugar, registram-se as estatuetas femininas de pequeno porte, de estilo naturalista, algumas com indicação de sexo, como seios e triângulos e retângulos na região pubiana, bastante semelhantes aos exemplares existentes nas culturas Santarém e Marajó, cuja função tem sido reconhecida como artefatos associados a cerimônias xamânicas de cura (Schaan 2001b). Alguns exemplares exibem sinais de quebra intencional, o que reforça a ideia de artefatos ritualmente quebrados, prática identificada nas culturas Marajoara (Schaan 2001b) e Santarém (Gomes 2010, 2016). Uma variação delas são as estatuetas disformes, sem identificação de sexo. Elas consistem em seres genéricos, cuja forma humana é basicamente sugerida. Um desses artefatos apresenta um furo, o que indica um instrumento provavelmente usado como cachimbo ou destinado à inalação de substâncias alucinógenas (Figura 10).

Figura 10: Estatuetas antropomorfas das Estearias do Maranhão. A - Estatueta antropomorfa disforme que consiste num cachimbo; B - Estatueta antropomorfa disforme; C, D, E, F: Fragmentos de estatuetas antropomorfas, sendo E com indicação de sexo feminino. Acervo Museu Nacional - UFRJ. Digitalização: Angislaine Freitas Costa. Fotos: Sarah Hissa
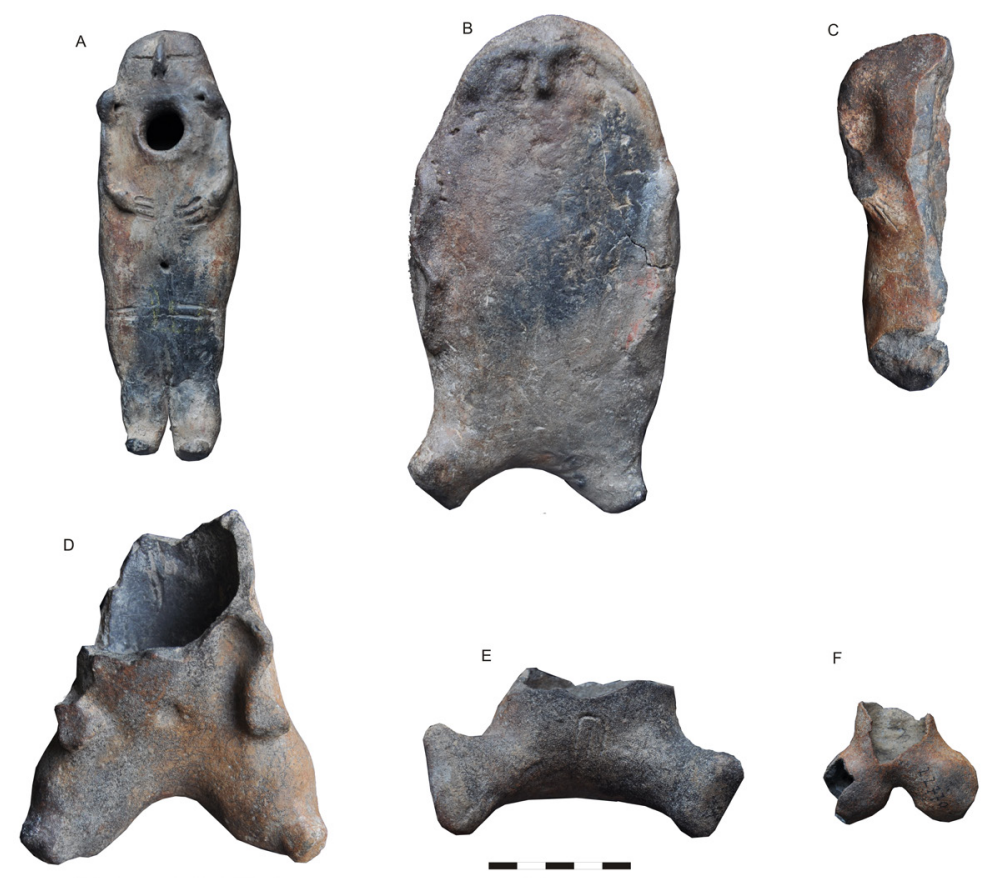
Existem ainda as vasilhas abertas de pequena a média capacidade volumétrica, destinadas tanto ao serviço individual quanto ao coletivo, apresentando pintura nas cores preta, vermelha sobre branco e vermelha e preta sobre branco, com grafismos abstratos - combinação de linhas horizontais e verticais; motivos espiralados; e motivos curvilíneos constituindo ondulações. Estes últimos são motivos contínuos e simétricos (Figura 11).

Figura 11: Padrões abstratos de pintura nas cores vermelha e preta de vasilhas das Estearias do Maranhão. A, B, D, E contêm elementos curvilíneos formando ondulações; C, F, G, H, I associam linhas paralelas a elementos curvilíneos. Acervo Museu Nacional - UFRJ. Digitalização: Angislaine Freitas Costa. Fotos: Sarah Hissa
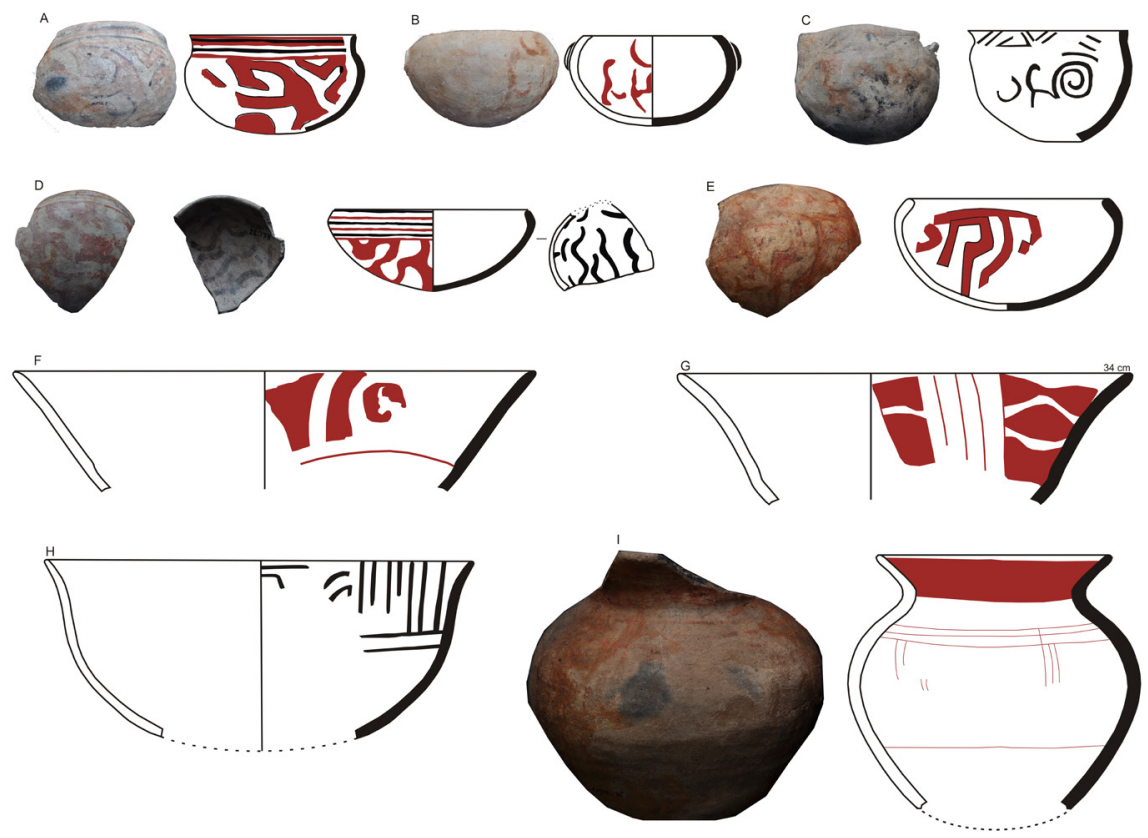

$--^{\mathrm{cm}}$

De modo geral, os artefatos rituais aqui analisados apontam para outro tipo de regime de objetos (Hugh-Jones 2009:35), menos elaborado no que concerne à estruturação das formas e das noções a elas associadas. Por outro lado, ainda que a cerâmica das Estearias Maranhenses seja mais simples em termos de formas e variabilidade de artefatos do que a cultura Santarém, ambas se sobressaem pela figuração e sintetizam a ideia de artefato-corpo. Entretanto, na cerâmica das estearias, ainda que se observe a predominância 
das efígies de animais, não há qualquer traço que remeta explicitamente à ideia de transformação corpórea, tão recorrente no estilo Santarém. Bastante sugestivas são as estatuetas disformes, que evocam a existência de outras subjetividades ou outros seres que simplesmente desconhecemos. Por fim, a abstração existente nos artefatos de serviço individual/coletivo também convive paralelamente com o outro modo de figuração dominante.

\section{Fabricando corpos, objetos e pessoas}

A recorrência da noção de artefato-corpo em diferentes culturas arqueológicas da Amazônia e sua vinculação aos processos de fabricação do corpo nas sociedades indígenas contemporâneas consistem numa chave interpretativa que possibilita pensar não só as especificidades dos sistemas gráficos da região, mas também permite evidenciar a continuidade temporal dessas noções aqui materializadas.

A partir da reflexão antropológica sobre a importância da construção do corpo entre as sociedades indígenas amazônicas é possível compreender a centralidade dessas noções, especialmente tendo em vista que ela se expande para os artefatos. Se os atos de concepção, de nutrição, os cuidados com o corpo, a coabitação, o uso de ornamentos e as atitudes rituais corporificadas visam construir pessoas (Seeger et al. 1979), a fabricação de artefatos no contexto das ontologias relacionais visa igualmente à construção de pessoas. Entretanto, essa relação tem sido pouco elaborada, com exceção dos trabalhos de Van Velthem $(1995,2003)$, Barcelos Neto $(2004,2008)$ e Lagrou $(1998$, $2009,2012)$. O primeiro trabalho a desenvolver o paralelismo entre a fabricação do artefato e do corpo no universo ameríndio foi o de Van Velthem (1995). Em ensaio comparativo sobre artefatos ameríndios, em diálogo com a obra de Gell, Lagrou (2009) mostra como este tema é recorrente no universo ameríndio.

Miller (2009:65) também amplia a noção de pessoa na Amazônia ao levar em conta o status dos objetos em contexto etnográfico. A autora discute o papel dos colares - ornamentos corporais e, nesse sentido, intimamente ligados aos corpos - entre os Mamaindê, do noroeste do Mato Grosso, estabelecendo que enquanto para estes os colares são sujeitos ou pessoas, para outros grupos da Chapada dos Pareci, também falantes de nambikwara, tanto os colares como as meninas adolescentes durante o período de reclusão são considerados objetos, no sentido de serem produto da ação humana.

Em consequência, a agência dos artefatos pode ser inferida etnograficamente não só no sentido de agência secundária dos objetos ou das mediações entre objetos e pessoas evidenciadas durante contextos rituais, conforme 
discutido por Gell (1998a), mas também a partir de uma existência animada e das propriedades agentivas diferenciadas desses artefatos (alguns possuem grande capacidade de comunicação e agência, outros são incapazes de ação direta), tendo em vista as teorias nativas de concepção de pessoa no mundo ameríndio (Santos-Granero 2009a:9-11).

Essa estreita relação entre objeto e corpo delineada por Miller (2009) também se expressa na ornamentação dos objetos. Hugh-Jones (2009), ao se referir aos objetos rituais na sociedade Tukano, correlaciona o modo como eles são decorados à pintura corporal: "A relação recursiva entre corpos e objetos é manifesta no fato dos objetos rituais serem decorados de maneira exata ao modo como os corpos são decorados: os mesmos desenhos são aplicados à cestaria, à pele dos dançarinos e aos bancos nos quais eles sentam" (Hugh-Jones 2009:49).

Desse mesmo modo é que Lagrou (2011a) também compreende a produção dos grafismos nos artefatos bidimensionais como uma pintura sobre o corpo e a produção ativa de artefatos tridimensionais como pessoas:

No traço bidimensional do grafismo os indígenas produzem peles, enquanto na fabricação tridimensional de artefatos produzem as roupas que seus Outros possam vestir para visitar o mundo visível. Esta conclusão aponta para um mundo onde não existem ídolos, porque o que se produz são corpos vivos, artefatos que são corpos e corpos que são artefatos (Lagrou 2011a:770).

Em trabalho recente, Lagrou (2016), ao tratar do papel dos ornamentos de miçangas entre os Kaxinawa e outros grupos amazônicos, enfatiza a superposição sistemática dos discursos ameríndios que dizem respeito aos artefatos e aos corpos, apontando a existência de um intenso entrelaçamento entre artefato e corpo, entre a fabricação de um corpo vivo e sua decoração exterior. Assim sendo, é possível entender de que modo a fabricação dos objetos segue fluxos semelhantes aos processos de fabricação do corpo nas sociedades indígenas contemporâneas. Ao que parece essas são noções com profundidade temporal, que estiveram presentes entre as sociedades pré-coloniais e orientaram os regimes de figuração dos artefatos.

Os conceitos de pessoa e humanidade aqui discutidos auxiliam a compreender a preeminência dos artefatos-corpo que seguem o esquema cabeça-cauda, que consistem em protótipos, em esquemas inacabados, incompletos de um corpo, mas que em contextos rituais (inacessíveis ao arqueológico) ativaram relações entre as pessoas. Ao lado das figurações que remetem à ideia de metamorfose corpórea, as figurações zoomorfas antropomorfizadas ou os seres híbridos, tão comuns no estilo cerâmico de Santarém, podem ser vistas enquanto índices da transformação corpórea. 
Essas figurações assinalam desse modo a ausência de categorias ontológicas fixas ou a instabilidade dos corpos, conforme proposto por Vilaça (2005), o que inspirou interpretações iconográficas nessa mesma linha, a exemplo de Alberti e Mashall (2009) e Alberti (2014), em relação aos artefatos da cultura Candelária do noroeste da Argentina.

Nos estilos figurativos amazônicos, a exemplo da arte cerâmica de Santarém, além das imagens que aludem à metamorfose corpórea, surgem ainda detalhes sutis, tais como as orelhas humanas que se assemelham a bicos de pássaros se vistas de lado (Gomes 2012). Estes podem ser considerados artifícios formais, equivalentes às técnicas de transformação visual presentes nos sistemas gráficos contemporâneos dominados pela abstração, que foram descritas por Lagrou (2013:66) como meios de atrair o olhar do expectador e induzi-lo a uma mudança de ponto de vista. No exemplo figurativo acima mencionado assim como na arte dos sistemas abstratos, guardadas as especificidades estilísticas, tais ideias são igualmente suscitadas.

\section{Conclusão: Da figuração à abstração}

Ainda que se reconheça a predominância das cosmologias animistas e perspectivistas entre os povos amazônicos, é possível destacar que eles possuem diferentes teorias e ideologias de materialidade e, nesse sentido, diferentes regimes de objetos, conforme discutido por Hugh-Jones (2009:35). As comparações estilísticas estabelecidas entre os objetos cerâmicos rituais de Santarém e das Estearias do Maranhão indicam não só especificidades formais, mas possivelmente distintas estruturas sociais e cosmológicas.

Comparando os estilos Santarém e das Estearias do Maranhão, o que eles têm em comum são os artefatos-corpo, artefatos com figurações zoomorfas desenvolvidos a partir da mesma concepção minimalista, os distintos tipos de estatuetas antropomorfas e o fato de os grafismos abstratos conviverem paralelamente com essas formas de figuração em épocas pré-coloniais. Os artefatos-corpo são as formas de figuração mais preeminentes tanto na cultura Santarém, nas Estearias do Maranhão, bem como em outras culturas da Amazônia e do Caribe. Nesse sentido, considerando a longa duração, é possível sustentar que esse modo de figuração de fato nunca foi abandonado, visto que, mesmo de maneira restrita, permanece na arte indígena contemporânea.

Em Santarém se observa a ocorrência de outros artefatos mais elaborados que parecem veicular noções bastante complexas, a exemplo de narrativas mitológicas (vasos de gargalo) e de modelos sobre a organização do 
cosmos em camada (vasos de cariátides). Eles podem ser entendidos como artefatos que consistem em sistemas de memória, conforme definido por Hugh-Jones (2016) ao se referir às várias formas iconográficas (petróglifos, pinturas nas paredes, cestarias etc.) presentes entre os Arawak e os Tukano no Alto Rio Negro, que consistem em suportes com função mnemônica de vários modos de história indígena ou mitos.

Tais vasos, encontrados no sítio Aldeia, em Santarém, e em diversos outros sítios da área de ocorrência dessa cultura, indicam a importância do xamanismo, das cerimônias coletivas e das possíveis redes de trocas de artefatos e de conhecimentos esotéricos. De modo complementar, as estatuetas realistas de homens sentados em bancos se afastam da ideia de instabilidade dos corpos e, ao contrário, indicam integridade corporal, possivelmente associada à importância política dos xamãs. Ainda que a arqueologia não possa recuperar as histórias de vida desses objetos e nem inferir sua condição de subjetividade, por analogia é possível supor que eles tiveram algum tipo de agência poderosa, considerando os contextos em que são recuperados - nas estruturas rituais intencionalmente cavadas.

Santos-Granero (2009a:18-19) aborda a condição ontológica dos objetos rituais descrevendo o ciclo de vida de objetos destinados a cerimônias xamânicas, e aponta que eles frequentemente são vistos como meios de materialização de subjetividades sobrenaturais. Sua fabricação, feita por especialistas, compreende operações destinadas a dar forma a entidades invisíveis, envolvendo segredo, práticas ascéticas, vigílias e abstinência sexual, além de numerosas precauções sobrenaturais. Em alguns casos, tais artefatos são vistos como portadores de uma alma poderosa e a eles se atribuem grande agência e poderes extraordinários.

O autor menciona ainda que objetos muito poderosos, uma vez quebrados ou incapazes de realizar suas tarefas, podem ser mutilados ou "magicamente mortos" antes de serem tirados de circulação. Este é precisamente o caso de Santarém, cujos contextos de retenção associados aos bolsões rituais contêm artefatos intencionalmente quebrados em grandes fragmentos, o que tem sido interpretado como a remoção de objetos do contexto cultural dinâmico a fim de evitar que eles afetem negativamente o conjunto das pessoas (Gomes 2010:228-229). Embora os contextos de deposição dos artefatos rituais das Estearias seja ambíguo, os sinais de quebra intencional das estatuetas femininas, vistas como artefatos xamânicos, permitem supor a existência desse mesmo tipo de agência.

Fausto e Severi (2016) discutem a agência dos objetos na cena ritual, enfatizando que eles partilham um campo relacional com outros atores, onde os objetos substituem a imagem do ser representado, convertendo-se em uma presença, o que vai muito além da ideia de representação icônica. 
Assim sendo, os autores destacam as dimensões pragmáticas e performáticas dos artefatos em contexto ritual, cuja agência de fato ultrapassa a noção de símbolo inerte e remete à dinâmica de produção de uma teia de relações sociais. Estas são questões muito importantes a serem consideradas pela arqueologia, cujo rendimento dependeria de contextos com grande detalhamento das atividades rituais.

Por outro lado, a arte das Estearias Maranhenses concentra-se no que parece ser a forma mais básica da figuração amazônica - as efígies zoomorfas, sendo inexistente qualquer modo mais explícito de materialização de ideias ligadas à transformação corpórea. As estatuetas antropormorfas, sobretudo as disformes, expõem os limites da abordagem representacional, o que nos leva a pensar na existência de outros mundos, outros seres e subjetividades inacessíveis à nossa cognição (Alberti \& Marshall 2009). Já algumas vasilhas de serviço individual e coletivo exibem pinturas com grafismos abstratos. Embora este tenha sido o padrão identificado nos objetos analisados a partir da coleção Raimundo Lopes - Museu Nacional-UFRJ, pesquisas recentes em sítios da baixada Maranhense recuperaram vasilhas com efígies zoomorfas também apresentando pintura com grafismos abstratos (Navarro 2016, comunicação pessoal), o que evidencia uma mudança em direção a um estilo híbrido, figurativo e ao mesmo tempo abstrato, de tipo semelhante a Marajó.

Assim, não se observa propriamente uma ruptura entre os regimes estéticos amazônicos pré-coloniais e os contemporâneos, uma vez que tanto a figuração como a abstração ocorrem em ambos. O que se coloca é uma diferença em grau, uma inversão temporal dessas formas de expressão artísticas, embora a ideia de artefato-corpo esteja presente na Amazônia de maneira contínua tanto na cerâmica como nos bancos, ainda que de modo minimalista. Enquanto nos dois exemplos pré-coloniais examinados neste artigo se observam o predomínio da figuração e a presença secundária dos grafismos abstratos, a abstração, por seu turno, se converte na principal forma de expressão da arte indígena contemporânea, conforme inicialmente apontado.

Esta análise, ao revelar a convivência de ambos os regimes de figuração em épocas pré-coloniais, mais uma vez recorda o argumento clássico da Antropologia da Arte sobre as relações existentes entre a abstração e a figuração elaborado por Boas (1996 [1927]:118-122). Em seu estudo das caixas de agulhas do Alasca, Boas mostrou que havia exemplos de formas abstratas, de animais representados de modo realista, de seres híbridos e formas de transição. A conclusão de Boas foi que a tendência em torno da abstração e da figuração realista era simultânea e que essas formas de figuração poderiam coexistir nessas sociedades tradicionais, mostrando que a direção de uma determinada perspectiva visual está sujeita a circunstâncias históricas. 
Uma possibilidade é que a preeminência generalizada da abstração na arte indígena amazônica contemporânea possa ter se fixado em contextos históricos de conquista colonial e que tal fenômeno estaria associado a estratégias deliberadas de resistência do xamanismo, convergindo para uma tendência de ocultação dos significados. No caso de Santarém, o desaparecimento dessas expressões figurativas mais elaboradas, intimamente ligadas ao xamanismo, implica não só uma mudança geral dos regimes de figuração dos objetos conforme observado, mas também o desaparecimento de formas mais complexas de organização social colocada em marcha por uma variada gama de processos voluntários e involuntários que vieram com a conquista europeia e, finalmente, pelas missões religiosas que se estabeleceram na Amazônia. Datações recentes obtidas em sítios cerâmicos portadores de artefatos cerimoniais na região de Santarém, tanto na área de Belterra (Stenborg 2016) como nas proximidades de Alter do Chão (Gomes 2016), indicam que esses modos de figuração aqui discutidos foram amplamente empregados até o século XVII, o que reforça a hipótese do impacto da conquista.

Recebido em 26 de abril de 2016

Aprovado em 08 de dezembro de 2016

Denise Maria Cavalcante Gomes é professora do Departamento de Antropologia, Programa de Pós-Graduação em Arqueologia, Museu Nacional, Universidade Federal do Rio de Janeiro, Rio de Janeiro, Brasil. e.mail: <denisecavalcante@ yahoo.com>

\section{Notas}

1 Agradecimentos: Este artigo é uma versão da palestra com o mesmo título proferida em 2014 nos Seminários Ameríndios do IFCS-UFRJ. Agradeço a Els Lagrou pelo convite e pela oportunidade em debater questões ligadas aos regimes de figuração da arte pré-colonial amazônica. Agradeço ainda às sugestões feitas por Cesar Gordon e Marco Antônio Gonçalves na mesma ocasião. Sou grata a Luciana Witowisk Gussella pelos desenhos, a Angislaine Freitas Costa pela digitalização dos grafismos e a Sarah Hissa pelas fotos. As pesquisas de campo e em coleções foram financiadas pelo CNPq (Processos: 151577/2005-6; 473224/2006-2; 408628/2013-8) e Fapesp (Processos: 96/0998-7; 08/58701-6). Agradeço ainda às valiosas sugestões dos dois pareceristas anônimos. 


\section{Referências bibliográficas}

ALBERTI, Benjamin. 2014. "Designing body pots in the formative La Candelaria Culture. Northwest Argentina". In: Elizabeth Hallam \& Tim Ingold (eds.), Making and growing: anthropological studies of organisms and artefacts. Abingdon-on-Thames: Routledge. pp. 107-125.

\& MARSHALL, Yvonne. 2009.

"Animating archaeology: local theories and conceptually open-ended methodologies". Cambridge Archaeological Journal, 19(3):345-357.

BARCELOS NETO, Aristóteles. 2004. Apapaatai. Rituais de máscaras no Alto Xingu. Tese de Doutorado, Universidade de São Paulo.

.2008. Apapaatai. Rituais de máscaras no Alto Xingu. São Paulo: Edusp.

BARATA, Frederico. 1950. A arte oleira dos Tapajó I. Considerações sobre a cerâmica e dois tipos de vasos característicos. Belém: Instituto de Antropologia e Etnologia do Pará. . 1951. "A arte oleira dos Tapajó II. Os cachimbos de Santarém". Revista do Museu Paulista, Nova série, 5:183-198.

. 1953a. "Uma análise estilística da cerâmica de Santarém". Cultura, 5:185-205.

. 1953b. A arte oleira dos Tapajó III. Alguns elementos para a tipologia de Santarém. Belém: Instituto de Antropologia e Etnologia do Pará.

BARRETO, Cristiana Nunes Galvão. 2008. Meios místicos de reprodução social: arte e estilo na cerâmica funerária da Amazônia Antiga. Tese de Doutorado em Arqueologia, Universidade de São Paulo.

BELAUNDE, Luisa Elvira. 2013. "Movimento e profundidade no kene shipibo-konibo da Amazônia peruana". In: Carlo Severi \& Els Lagrou (orgs.), Quimeras em diálogo: grafismo e figuração nas artes indígenas. Rio de Janeiro: 7Letras. pp. 199-222.
BETENDORF, João Felipe. 1910. Chronica da missão dos padres da Companhia de Jesus no Estado do Maranhão. Revista do Instituto Histórico e Geográfico Brasileiro, 72(1):1-679.

BOAS, Franz. 1996 [1927]. "A arte da costa do Pacífico Norte da América do Norte". In: Arte primitiva. Lisboa: Fenda. pp. 174-283.

BOOMERT, Arie. 2001. "Raptorial birds as icons of shamanism in the prehistoric Caribbean and Amazonia". XIX International Congress for Caribbean Archaeology, Aruba, N. A. pp. 121157. Mimeo.

CORRÊA, Conceição G.; MACHADO, Ana Lúcia \& LOPES, Daniel F. 1991. "As estearias do Lago Cajari - MA". Clio, Simpósio de Pré-história do Nordeste Brasileiro, 1. pp. 101-103. Mimeo.

DANIEL, João. 1976. Tesouro descoberto no Rio Amazonas. Rio de Janeiro: Biblioteca Nacional.

DESCOLA, Philippe. 2005. Par de là nature et Culture. Paris: Gallimard.

FAUSTO, Carlos. 2013. "A máscara do animista: quimeras e bonecas russas na América indígena". In: Carlo Severi \& Els Lagrou, Quimeras em diálogo: grafismo e figuração na arte indígena. Rio de Janeiro: 7Letras. pp. 305- 331.

. \& SEVERI, Carlo. 2016. "Introdução: de imagens e palavras". In: Palavras em imagens: escrita, corpos e memórias. Marseille: OpenEdition Press. Baixado em 9 de dezembro de 2016. Disponível em: http://books. openedition.org/oep/1292. ISBN: 9782821855779. DOI: 10.4000/books. oep.1292.

GELL, Alfred. 1992. "The technology of enchantment and the enchantment of technology". In: J. Coote \& A. Shelton (eds.), Anthropology and aesthetics. Oxford: Claredon Press. pp. 40-63. 
. 1998. Art and agency, an anthropological theory. Oxford: Oxford University Press.

GOMES, Denise Maria Cavalcante. 2001. "Santarém: symbolism and power in the tropical forest". In: C. McEwan; C. Barreto \& E. Neves (eds.), The unknown Amazon. London: British Museum Press. pp. 134-55.

2002. Cerâmica arqueológica da Amazônia: vasilhas da Coleção Tapajônica do MAE-USP. São Paulo: Edusp/Fapesp /Imprensa Oficial. . 2007. "The diversity of social forms in pre-colonial Amazonia". Revista de Arqueologia Americana, 25:189-225. . 2010. "Os contextos e os significados da arte cerâmica dos Tapajó". In: E. Pereira \& V.L.C. Guapindaia (eds.), Arqueologia amazônica (vol. 1). Belém: Museu Paraense Emílio Goeldi/Secult/Iphan. pp. 213-34.

. 2011. "Cronologia e conexões culturais na Amazônia". Revista de Antropologia, 54(1):269-314.

. 2012. "O perspectivismo ameríndio e a ideia de uma estética americana". Boletim do Museu Paraense Emílio Goeldi - Ciências Humanas, 7(1):33-59.

. 2016. "Politics and ritual in large villages in Santarém, lower Amazon, Brazil". Cambridge Archaeological Journal, pp. 1-19. doi: 10.1017/ S0959774316000627. http://www. cambridge.org/core. Endereço do IP: 179.86.70.25, baixado em 9/12/2016, sujeito aos termos de core Cambridge, disponíveis em http://www. cambridge.org/core/terms.

. \& LUIZ, José Gouvêa. 2013. "Contextos domésticos no sítio arqueológico do Porto, Santarém, Brasil, identificados com o auxílio da geofísica por meio do método GPR". Boletim do Museu Paraense Emílio Goeldi - Ciências Humanas, 8(3):639-656.
GORDON, César. 2011. “Em nome do belo: o valor das coisas xikrin-mebêngôkre". In: Fabíola Andréa Silva \& César Gordon (orgs.), Xikrin: uma coleção etnográfica. São Paulo: Edusp. pp. 207-223.

GOW, Peter. 1989. "Visual compulsion: design and image in Western Amazonian art". Revindi, Revista Indigenista Americana, 2:19-32.

GUAPINDAIA, Vera Lúcia Calandrini. 1993. Fontes históricas e arqueológicas sobre os Tapajó de Santarém: a coleção "Frederico Barata" do Museu Paraense Emílio Goeldi. Dissertação de Mestrado em História, Universidade Federal de Pernambuco, Recife. . 2001. "Encountering the ancestors: the Maracá urns". In: Collin McEwan; Cristiana Barreto \& Eduardo Neves (orgs.), The unknown Amazon. Culture and nature in ancient Brazil. Londres: The British Museum Press. pp. 156-173.

. 2008. Além da margem do rio - as ocupações Konduri e Pocó na região de Porto Trombetas, PA. Tese de Doutorado, Universidade de São Paulo.

HECKENBERGER, Michael. 2005. The ecology of power: culture, place and personhood in the Southern Amazon, A.D. 1000-2000. New York: Routledge.

HUGH-JONES, Stephen. 1994. "Shamans, prophets, priests and pastors". In: Nicholas Thomas \& Caroline Humphrey (eds.), Shamanism, history and the State. Ann Harbour: University of Michigan Press. pp. 32-75. . 2009. "The fabricated body: objects and ancestors in Northwest Amazonia". In: F. Santos Granero (org.), The occult life of things: native Amazonian theories of materiality and personhood. Tucson: University of Arizona Press. pp. 33-59.

. 2016. "Escrita nas pedras, escrita no papel (Noroeste da Amazônia)". 
In: Carlos Fausto \& Carlo Severi, Palavras em imagens: escrita, corpos e memórias. Marseille: OpenEdition Press. Baixado em 9 de dezembro de 2016. Disponível em: http:// books.openedition.org/oep/1274. ISBN:9782821855779. DOI: 10.4000/ books.oep.1274.

LAGROU, Els. 1996. "Xamanismo e representação entre os Kaxinawá". In: Esther J. Langdon (org.), Xamanismo no Brasil: novas perspectivas. Florianópolis: Editora UFSC. pp.197-231. . 1998. Caminhos, duplos e corpos. Uma abordagem perspectivista da identidade e alteridade entre os Kaxinawa. Tese de Doutorado, São Paulo, USP.

.2002. "O que nos diz a arte kawinawa sobre a relação entre identidade e alteridade?". Mana. Estudos de Antropologia Social, 8(1):29-62 .2007. A fluidez da forma. Arte, alteridade e agência em uma sociedade amazônica (Kaxinawa, Acre). Rio de Janeiro: Topbooks.

. 2009. Arte indígena no Brasil: agência, alteridade e relação. Belo Horizonte: ComArte.

. 2011a. "Le graphisme sur les corps amérindiens. Des chimères abstraites?". Gradhiva, 13:69-93.

. 2011b. "Existiria uma arte das sociedades contra o Estado?". Revista de Antropologia, 54(2):747-780.

. 2012. "Perspectivismo, animismo y quimeras: una reflexión sobre el grafismo ameríndio como técnica de alteración de la percepción". Mundo Amazónico, 3:54-78.

. 2013. "Podem os grafismos ameríndios ser considerados quimeras abstratas?: uma reflexão sobre uma arte perspectivista. In: Carlo Severi \& Els Lagrou (orgs.), Quimeras em diálogo: grafismo e figuração na arte indígena. Rio de Janeiro: 7Letras. pp. 67-109.

. 2016. "Um corpo feito de artefatos: o caso da missanga". In: Carlos Fausto \& Carlo Severi (orgs.), Palavras em imagens: escrita, corpos e memórias. Marseille: OpenEdition Press. Baixado em 9 de dezembro de 2016. Disponível em: http://books.openedition. org/oep/823. ISBN: 9782821855779. DOI: $10.4000 /$ books.oep.823.

LEITE FILHO, Deusdédit C. 2010. "Ocupações pré-coloniais no litoral e nas bacias lacustres no Maranhão". In: Edith Pereira \& Vera Lúcia C. Guapindaia (orgs.), Arqueologia amazônica 2. Belém: MPEG/Iphan/ Secult. pp. 771-773.

LÉVI-STRAUSS, Claude. 1976. O pensamento selvagem. São Paulo: CEN.

LOPES, Raymundo. 1924. "A civilização lacustre no Brasil". Boletim do Museu Nacional, 1(2):87-109. . 1931. "Entre a Amazônia e o sertão". Boletim do Museu Nacional, 7:159-186. . 1970. Uma região tropical. Rio de Janeiro: Seleta.

MACDONALD, Regina. 1972. "The order of things: an analysis of the ceramics from Santarém, Brazil". Journal of the Steward Anthropological Society, 4(1):39-55.

MILLER, Joana. 2009. "Things as persons: body ornaments and alterity among the Mamaindê (Nambikwara)". In: F. Santos Granero (org.), The occult life of things: native Amazonian theories of materiality and personhood. Tucson, Arizona: Arizona University Press. pp. 69-97.

MÜLLER, Regina Porto. 1992. “Tayngava, a noção de representação na arte gráfica Assurini do Xingu". In: Lux Vidal (org.), Grafismo indígena. São Paulo: Studio Nobel/Fapesp/Edusp. pp. 231-246.

NAVARRO, Alexandre Guida. 2013. "O povo das águas: carta arqueológica das estearias da porção centro-norte da baixada maranhense". Cadernos de Pesquisa, 20(3):57-65. 
. 2015. "Pré-história da Baixada Maranhense: datação radiocarbônica de cinco estearias". In: Adriana Zierer; Ana Lívia B. Vieira \& Elizabeth S. Abrantes (orgs.), História antiga e medieval, sonhos e mitos e heróis: memória e identidade. São Luiz: Editora Uema. pp. 369-380.

NEVES, Eduardo Góes. 2006. Arqueologia da Amazônia. Rio de Janeiro: Jorge Zahar.

. 2008. "Ecology, ceramic chronology and distribution, long-term history and political change in the Amazonian floodplain". In: H. Silverman \& W. Isbell (orgs.), Handbook of South American archaeology. New York: Springer. pp. 359-379.

NIMUENDAJU, Curt. 1949. "Os Tapajó". Boletim do Museu Paraense Emílio Goeldi, 10:93-106.

. 2004. In pursuit of a past Amazon: archaeological researches in the Brazilian Guyana and in the Amazon region. A Posthumous Work Compiled and Translated by Stig Rydén and Per Stenborg. Götenborg: Världskulturmuseet i Göteborg.

PALMATARY, Hellen. 1960. "The archaeology of the Lower Tapajós Valley, Brazil". Transactions of the American Philosophical Society, 50(3):1-246.

QUINN, Ellen. 2004. Excavating “Tapajó" ceramics at Santarém: their age and archaeological context. Unpublished Doctoral Thesis, University of Illinois at Chicago, Chicago.

RICE, Prudence. 1987. Pottery analysis: $a$ sourcebook. Chicago: The University of Chicago Press.

ROOSEVELT, Anna. 1988. "Interpreting certain female images in prehistoric art". In: V.E. Miller (ed.), The role of gender in precolumbian art and architecture. Labham: University Press of America. pp. 1-34

. 1991. Moundbuilders of the Amazon: geophysical archaeology on Marajo island, Brazil. San Diego: Academic Press.
1992. "Arqueologia amazônica". In: Manuela Carneiro da Cunha (org.), História dos índios do Brasil. São Paulo: Editora Cia. das Letras. pp. 53-86. . 1999. "Complex polities in the ancient tropical world". In: E.A. Bacus \& L.C. Lecero (eds.), Archaeological Papers of the American Anthropological Association, 9:13-33.

ROSTAIN, Sthephen. 2010. "Precolumbian earthworks in Costal Amazonia". Diversity, 2(3):331-352.

SANTOS GRANERO, Fernando. 2009a. Introduction. In: _.. (org.), The occult life of things. Native Amazonian theories of materiality and personhood. Tucson: The University of Arizona Press. pp. 1-29. . 2009b. "From baby slings to feather bibles and from Star utensils to jaguar stones". In: __. (org.), The occult life of things. Native Amazonian theories of materiality and personhood. Tucson: The University of Arizona Press. pp. 105-127.

SCHAAN, Denise Pahl. 1997. A linguagem iconográfica da cerâmica marajoara: um estudo da arte pré-histórica da Ilha de Marajó, Brasil (400-1300 $A D)$. Porto Alegre: Edipuc/RS.

. 2001a. "Into the labyrinths of Marajoara pottery: status and cultural identity in prehistoric Amazonia". In: Collin McEwan; Cristiana Barreto \& Eduardo Neves (eds.), The unknown Amazon. Culture and nature in ancient Brazil. Londres: The British Museum Press. pp. 108-133. . 2001b. "Estatuetas antropomorfas marajoara: o simbolismo de identidades de gênero em uma sociedade complexa amazônica". Boletim do Museu Paraense Emílio Goeldi, Série Antropologia, 17(2):23-63.

. 2004. The Camutins Chiefdom: rise and development of social complexity on Marajó Island, Brazilian Amazon. Unpublished Doctoral Dissertation, University of Pittsburg. 
2008. "The nonagricultural chiefdoms of Marajó Island". In: H. Silverman \& W.H. Isbell (eds.), Handbook of South American archaeology. New York: Springer. pp. 339-357.

. 2016. "Discussing centre-periphery relations within the Tapajó domain, Lower Amazon". In: P. Stenborg (ed.), Beyond waters: archaeology and environmental history of the Amazonian Inland. Gotarc Series A, Gothenburg Archaeological Studies 6. Gothenburg: University of Gothenburg. pp. 23-36.

SCHAAN, Denise Pahl \& ALVES, Daiana Travassos (orgs.). 2015. Um porto, muitas histórias: arqueologia em Santarém. Belém: Gráficas Superiores.

SEEGER, Anthony; DA MATTA, Roberto \& VIVEIROS de CASTRO, Eduardo. 1979. "A construção da pessoa nas sociedades indígenas brasileiras". Boletim do Museu Nacional, 32:1-20.

SIMÕES, Mário. 1981. "As pesquisas arqueológicas no Museu Paraense Emílio Goeldi (1870-1981)". Acta Amazonica, 11(1):149-165.

SIMÕES, Mário \& ARAUUJO COSTA, Fernanda. 1978. Áreas da Amazônia legal brasileira para pesquisa e cadastro de sítios arqueológicos. Belém: Publicações Avulsas do Museu Goeldi.

STENBORG, P. 2016. "Towards a regional history of Pre-Columbian settlements in the Santarém and Belterra regions, Pará, Brazil". In: . (ed.), Beyond waters: archaeology and environmental history of the Amazonian inland. Gotarc Series A Gothenburg Archaeological Studies 6. Gothenburg: University of Gothenburg. pp. 9-20.

TAYLOR, Anne Christine \& VIVEIROS DE CASTRO, Eduardo. 2006. "Un corps fait de regards". In: Stephanie Breton (org.), Qu'est-ce qu'un corps?: Amazonie. Paris: Musée du Quai Branly/ Flammarion. pp. 148-199.
VAN VELTHEM, Lucia. 1995. O belo é a fera. A estética da produção e da predação entre os Wayana. Tese de Doutorado, Universidade de São Paulo. . 2001. "The Woven universe: Carib basketry". In: Collin McEwan; Cristiana Barreto \& Eduardo Neves (eds.),Unknown Amazon: culture and nature in ancient Brazil. Londres: The British Museum Press. pp. 198-213. . 2003. O belo é a fera. A estética da produção e da predação entre os Wayana. Lisboa: Editora Assírio \& Alvim.

. 2009. "Mulheres de cera, argila e arumã: princípios criativos e fabricação material entre os Wayana". Mana. Estudos de Antropologia Social, 15(1):213-236.

. 2013. "Homens, guaribas e artefatos: alguns sentidos da pintura entre os Wajana (Wayana)". In: Carlo Severi \& Els Lagrou (orgs.), Quimeras em diálogo: grafismo e figuração na arte indígena. Rio de Janeiro: 7Letras. pp. 139-161.

VIDAL, Lux. 1992. "A pintura corporal e a arte gráfica entre os Kayapó-Xikrin do Cateté". In: __. (org.), Grafismo indígena. São Paulo: Studio Nobel/ Fapesp/Edusp. pp. 143-189.

VILAÇA, Aparecida. 2005. "Chronically unstable bodies. Reflections on Amazonian corporalities". Journal of the Royal Anthropological Institute, 11(3):445-464.

VIVEIROS DE CASTRO, Eduardo. 1996. "Os pronomes cosmológicos e o perspectivismo ameríndio". Mana. Estudos de Antropologia Social, 2(1):115-144. . 2002. A inconstância da alma selvagem, e outros ensaios de antropologia. São Paulo: Cosac \& Naify. . 2004. "Exchanging perspectives: the transformation of objects into subjects in amerindian ontologies". Common Knowledge, 10(3):463-484. 


\section{O LUGAR DOS GRAFISMOS E DAS REPRESENTAÇÕES NA ARTE PRÉ- COLONIAL AMAZÔNICA}

\section{Resumo}

Este artigo discute aspectos formais associados à materialidade dos regimes de figuração da cerâmica ritual de duas culturas pré-coloniais tardias da Amazônia - Santarém (1000-1600 d.C.) e as Estearias do Maranhão (775-1045 d.C.) - cujos objetos se sobressaem pela ênfase nas representações figurativas. Seu propósito é evidenciar a estrutura de ambos os estilos e finalmente refletir sobre os possíveis significados culturais da inversão observada nessas sociedades do passado em relação à arte das sociedades indígenas contemporâneas. Segundo a recente caracterização antropológica, esta última seria marcada por uma tendência geral não representativista que se destaca pela presença do grafismo abstrato, mantendo uma conexão com as cosmologias animistas e perspectivistas dominantes na região. Vistos em detalhe, os exemplos arqueológicos examinados, apesar de indicarem uma tendência oposta ou a preeminência da figuração, apontam a coexistência de ambos os regimes.

Palavras-chave: Arte pré-colonial, Amazônia, Materialidade, Figurativismo, Abstração, Santarém, Estearias do Maranhão.

\section{EL LUGAR DE LOS GRAFISM OS Y DE LAS REPRESENTACIONES EN EL ARTE PRECOLONIAL AMAZÓNICO}

\section{Resumen}

Este artículo aborda aspectos formales relacionados con la materialidad de los regímenes de figuración de la cerámica ritual de dos culturas precoloniales de la Amazonia - Santarém (1000-1600 d.C.) y Estearias del Maranhão (775-1045 d.C.) - cuyos objetos se destacan por el énfasis en las representaciones figurativas. Su propósito es poner de relieve la estructura de ambos estilos y finalmente reflexionar sobre el posible significado cultural de esta inversión observada en el pasado, en comparación con el arte contemporáneo de las sociedades indígenas. Según la caracterización antropológica reciente, este último estaría marcado por una tendencia general no representacional que se destaca debido a la presencia de los grafismos abstractos, manteniendo una conexión con las cosmologías perspectivistas y animistas dominantes en la región. Vistos en detalle, los ejemplos arqueológicos aunque indiquen una tendencia opuesta o la preeminencia de la figuración, sugieren la coexistencia de ambos regímenes.

Palabras clave: Arte precolonial, Amazonia, Materialidad, Figurativismo, Abstracción, Santarém, Estearias del Maranhão. 
THE PLACE OF ABSTRACT DESIGN AND REPRESENTATIONS IN AMAZONIAN PRE-COLONIAL ART

\begin{abstract}
This article discusses formal aspects of the materiality of figurative ceramic art schemes in two late pre-colonial cultures of the Amazon - Santarém (A.D. 10001600) and the Estearias of Maranhão (A.D. 775-1045), whose material culture stands out for its emphasis on figurativism. Its purpose is to highlight the formal structure of both styles and to reflect on the cultural meanings of the
\end{abstract}

tendency for reversals observed in these ancient societies when compared to the art of contemporary indigenous societies. According to recent anthropological characterization, the latter would be marked by a general non-representative trend that is noteworthy for its abstract designs, maintaining a connection with the animist and perspectivist cosmologies dominant in the region. Considered in detail, the archaeological examples investigated in this article indicate the prominence of figurativism, but suggests the coexistence of both regimes.

Key-words Pre-colonial Art, Amazonia, Materiality, Figurativism, Abstractionism, Santarém, Estearias of Maranhão. 